Invited review

\title{
Tidal sand bar dimensions and shapes in estuaries
}

\author{
J.R.F.W. Leuven *, M.G. Kleinhans, S.A.H. Weisscher, M. van der Vegt
}

Faculty of Geosciences, Utrecht University, PO Box 80115, 3508 TC Utrecht, The Netherlands

\section{A R T I C L E I N F O}

\section{Article history:}

Received 10 March 2016

Received in revised form 3 August 2016

Accepted 9 August 2016

Available online 15 August 2016

\section{Keywords:}

Estuary

Sand bars

Bar pattern

Bar dimensions

Braiding index

Linear stability analysis

\begin{abstract}
A B S T R A C T
Estuaries show dynamic patterns of channels and bars, which are also valuable habitats, while channels provide access to harbours. In contrast with bars in rivers, we still lack explanations, theory and classifications for bars in estuaries. Theories for river bars show bar properties to be strongly dependent on channel width-to-depth ratio. For estuaries, only two physics-based theories are available. One predicts bar length to increase with flow velocity and tidal excursion length and the other with flow velocity and estuary width. However, these theories have not been tested for lack of data and experiments. Our objective is to determine bar shape and dimensions in funnel shaped alluvial estuaries and to provide predictive relations for bar shapes and dimensions. We present a new dataset measured in imagery and bathymetry with bar lengths spanning from centimetres (in experiments) to tens of kilometres. We visually identified and classified 190 bars and measured their width, length, height and number of cross-cutting barbs channels. Estuarine geometry and tidal characteristics were obtained from available databases and literature. We found that many compound bars can be seen as simple linear bars partly cut by barb channels, where partitioning of bar width collapses the data of bar length-to-width ratio. This is in agreement with the transverse wave form of bars assumed in linear stability theories that are supported by data in fluvial and coastal environments. Our empirical trend shows that sand bars in estuaries have similar length-to-width ratios as river bars but are more elongated. This trend was also found to hold for bars in numerical models and scaled laboratory experiments. Bar height is linearly related to local water depth. Natural bar length, bar width and braiding index are strongly correlated to estuary width. This relation is also evident in published data of bars in rivers and numerical models of rivers. The theoretical braiding index of tidal bars indeed depends on local width-todepth ratio and is reasonably well predicted for our dataset. However, the theoretical models for tidal bar wave length and width surprisingly lack this correlation with estuary width and overpredict by an order of magnitude, pointing at a need to revisit tidal bar theory. The empirical relations provide a means of estimating bar dimensions when limited data are available and in order to evaluate results from numerical models and physical experiments.

(c) 2016 Elsevier B.V. All rights reserved.
\end{abstract}

\section{Contents}

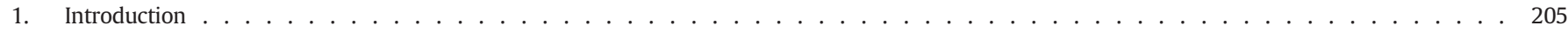

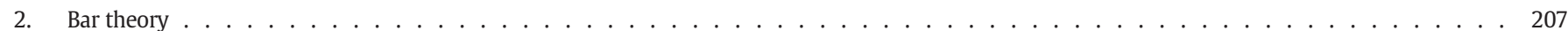

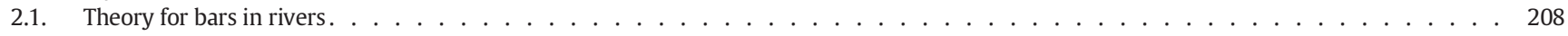

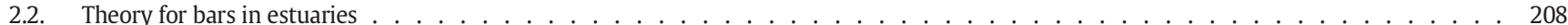

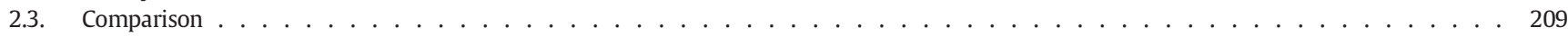

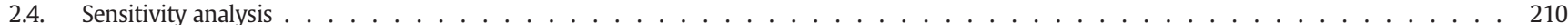

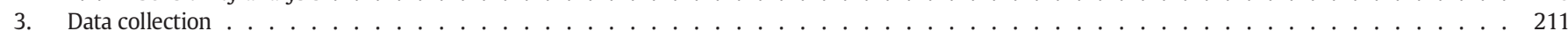

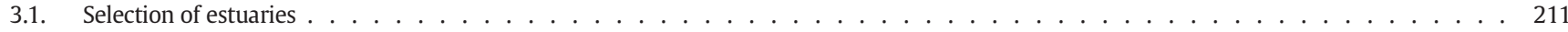

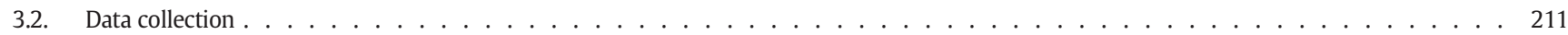

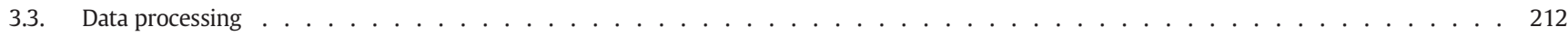

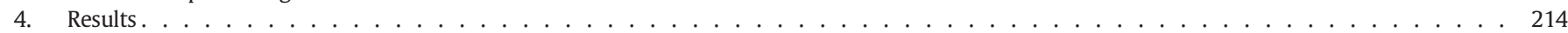

4.1. Bar shapes and dimensions . . . . . . . . . . . . . . . . . . . . . . . . . . . . . . . . . . 214

4.2. Relation between bar dimensions and estuarine properties . . . . . . . . . . . . . . . . . . . . . . . . . . . . . . . 215

4.3. Dependence of bar shape and braiding index on water level . . . . . . . . . . . . . . . . . . . . . . . . 216

4.4. Comparison of theory and data . . . . . . . . . . . . . . . . . . . . . . . . . . . . . . . . 217

\footnotetext{
* Corresponding author.

E-mail address: j.r.f.w.leuven@uu.nl (J.R.F.W. Leuven).
} 


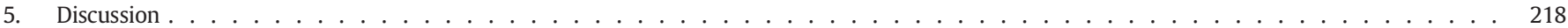

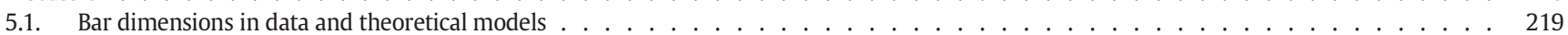

5.2. Applicability of the theoretical models . . . . . . . . . . . . . . . . . . . . . . . . . 219

5.3. What determines bar properties? . . . . . . . . . . . . . . . . . . . . . . . . . . . . . . 220

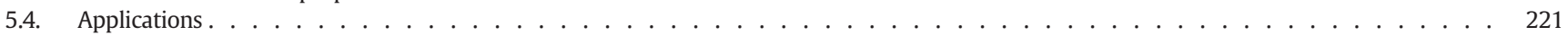

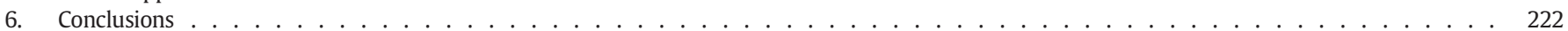

Acknowledgments . . . . . . . . . . . . . . . . . . . . . . . . . . . . . . . 222

Appendix A. Supplementary data . . . . . . . . . . . . . . . . . . . . . . . . . . . . . . . 222

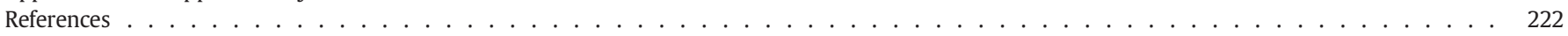

\section{Introduction}

An estuary is a body of water that has inflow of river water at the landward boundary and an open connection to the sea. Many definitions and classifications have been proposed for estuaries, which mostly depend on their application (Pritchard, 1967; Hume and Herdendorf, 1988; Davidson and Council, 1991; Dalrymple et al., 1992; Perillo, 1995; Townend et al., 2000; Townend, 2005; Savenije, 2006). In most cases, estuaries were defined based on the relative influence of tides, waves, rivers, sediment types, sediment supply, vegetation, geology or time (see Savenije, 2006, for review).

Here we focus on funnel shaped alluvial estuaries that are characterised by complicated patterns of dynamic channels and sand bars, often flanked by tidal mud flats and salt marshes. Savenije (2006) defined alluvial estuaries as estuaries with erodible beds, influenced by both river flow and tidal flow from the sea. Therefore, the sediment bed of alluvial estuaries comprises both sediment types: the coarser fluvial sand and finer marine mud. Depending on the relative
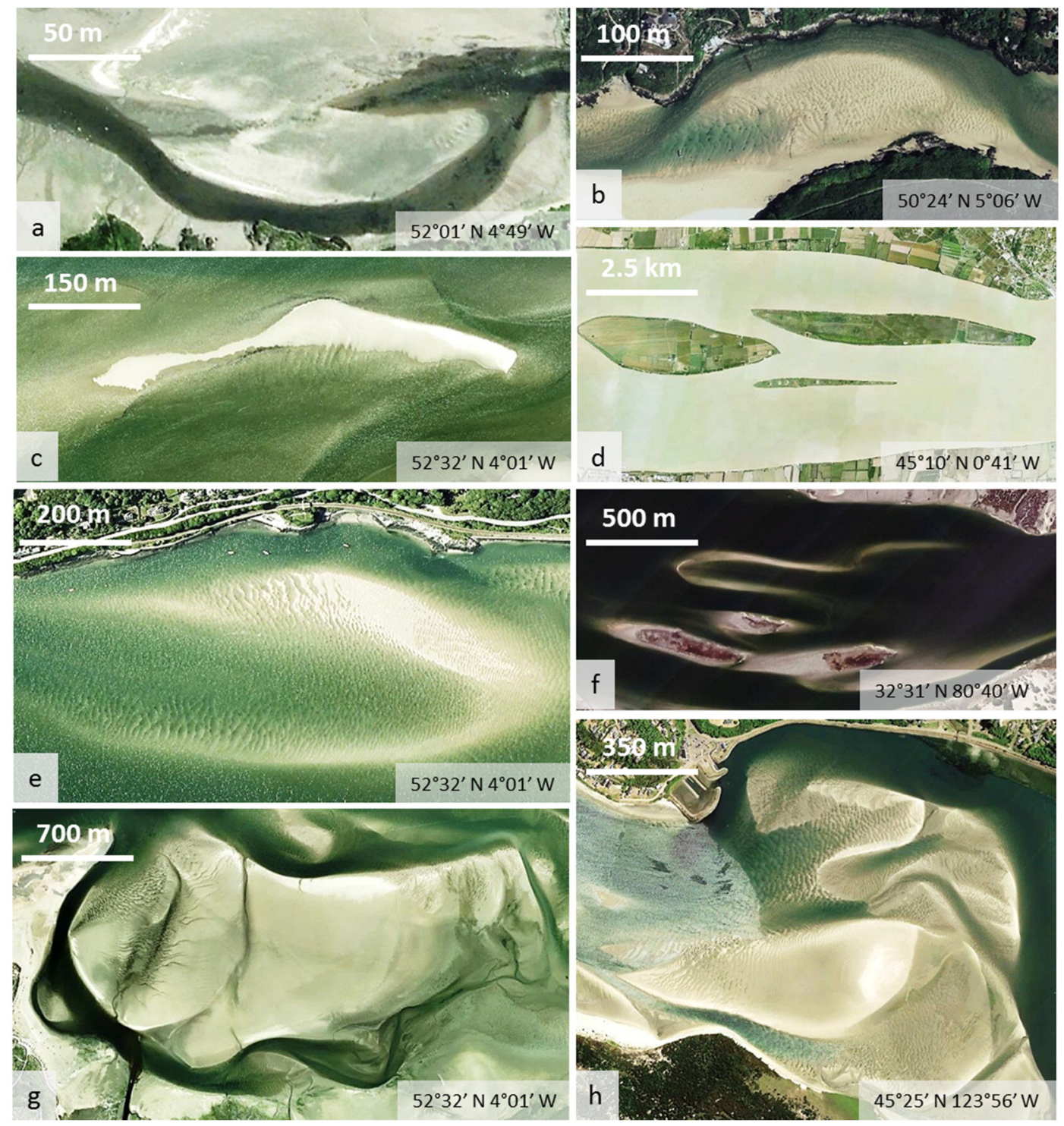

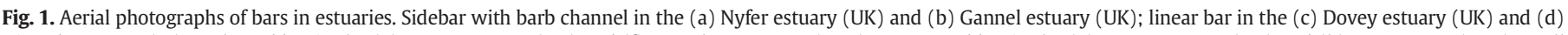

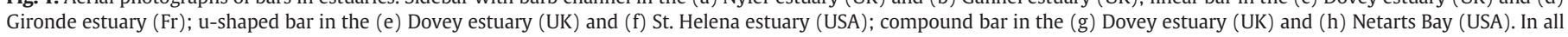
cases flood flow is from left to right. Google Earth, accessed May-September 2015. 
importance of the hydrodynamic processes, one can further discriminate between river-dominated and tidal-dominated estuaries. Nevertheless, data to assess this are often lacking and if data is available, the question rises what defines for example the threshold for fluvial dominance. Dynamic sand bar patterns can form when the estuary received sufficient fluvial sediments. Our main question is: what determines the bar pattern in funnel shaped alluvial estuaries?

The understanding of bar patterns is relevant for the management of channels, which are used as shipping fairways, and bars or shoals, which are valuable ecological habitats (Wang et al., 2012; Coco et al., 2013). Furthermore, tidal sand bar deposits form large and complicated hydrocarbon reservoirs of which architecture is difficult to reconstruct from limited data (Wood, 2004).

Sand bars, also called shoals, occur in a wide variety of shapes: from long and narrow to circular or squared, and in a variety of size, from meters to kilometres (Fig. 1). In contrast with estuaries, detailed classifications exist for river bars (Fig. 2), along with a description of the forming mechanisms (Cant and Walker, 1978; Bridge, 1993; Ashworth et al., 2000; Bridge, 2003; Sambrook Smith et al., 2006; Kelly, 2006; Rice et al., 2009; Kleinhans and van den Berg, 2011; Schuurman et al., 2013). Most classifications discriminate between simple unit bars and compound bars. Unit bars are small (100-300 m) bars with a lobate shape that have their highest point at the downstream end followed by a steep face (e.g. Sambrook Smith et al., 2006). Compound bars comprise
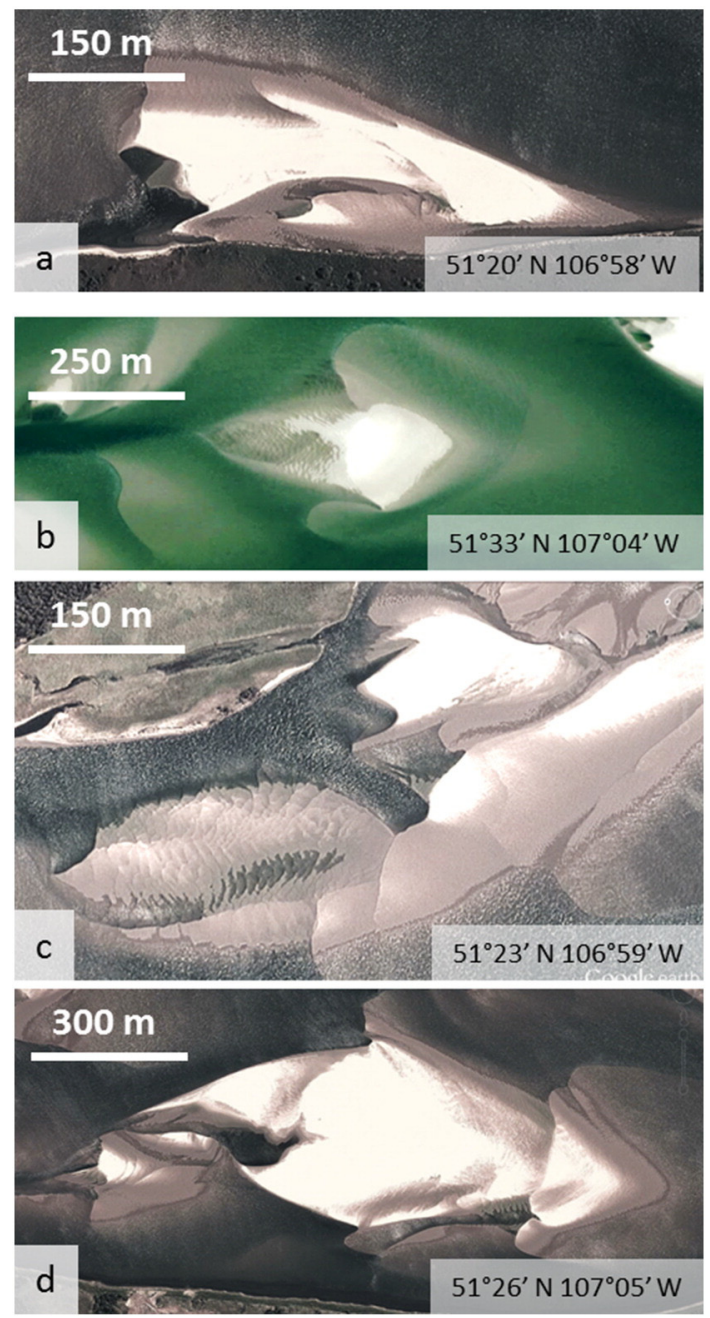

Fig. 2. Aerial photographs of river bars in the Saskatchewan river near Outlook (Canada): (a) side bar; (b) compound bar amalgamated from a few smaller unit bars; (c) chute bars; (d) compound mid-channel bar. Compare respectively to Fig. 1a,b, c,d, e,f, g,h. Google Earth, accessed May-September 2015. multiple amalgamated unit bars and formed by several stages of erosion and deposition (e.g. Bridge, 2003; Ashworth et al., 2000; Schuurman et al., 2013). Therefore, they occur in a wider variety of shapes and are generally larger than unit bars, for example forming sidebars and bars with a u-shape (Fig. 2).

It is unknown to what extent tidal bars in estuaries have similar dimensions, shapes and forming mechanisms as bars in estuaries. For estuaries, van Veen (1950) and Dalrymple and Choi (2007) defined three different types: linear bars, u-shaped bars and sidebars (Fig. 3). All other bars in estuaries, which are more complex bars that probably amalgamated from other bars, we define here as compound bars (Fig. 1g,h) in analogy with rivers.

In all these definitions we describe bars as discrete recognisable elements on what is essentially a continuous field of bed elevation that changes over time. In contrast to the situation of merging bars, of which the history is captured by the term amalgamated or compound bar, one bar can become two bars when a channel cuts through it with sufficient depth, meaning that the history of these bars being one bar is lost. In rivers such deep channels are called chute channels. Moreover, an intermediate stage is recognised as cross-bar channels, which
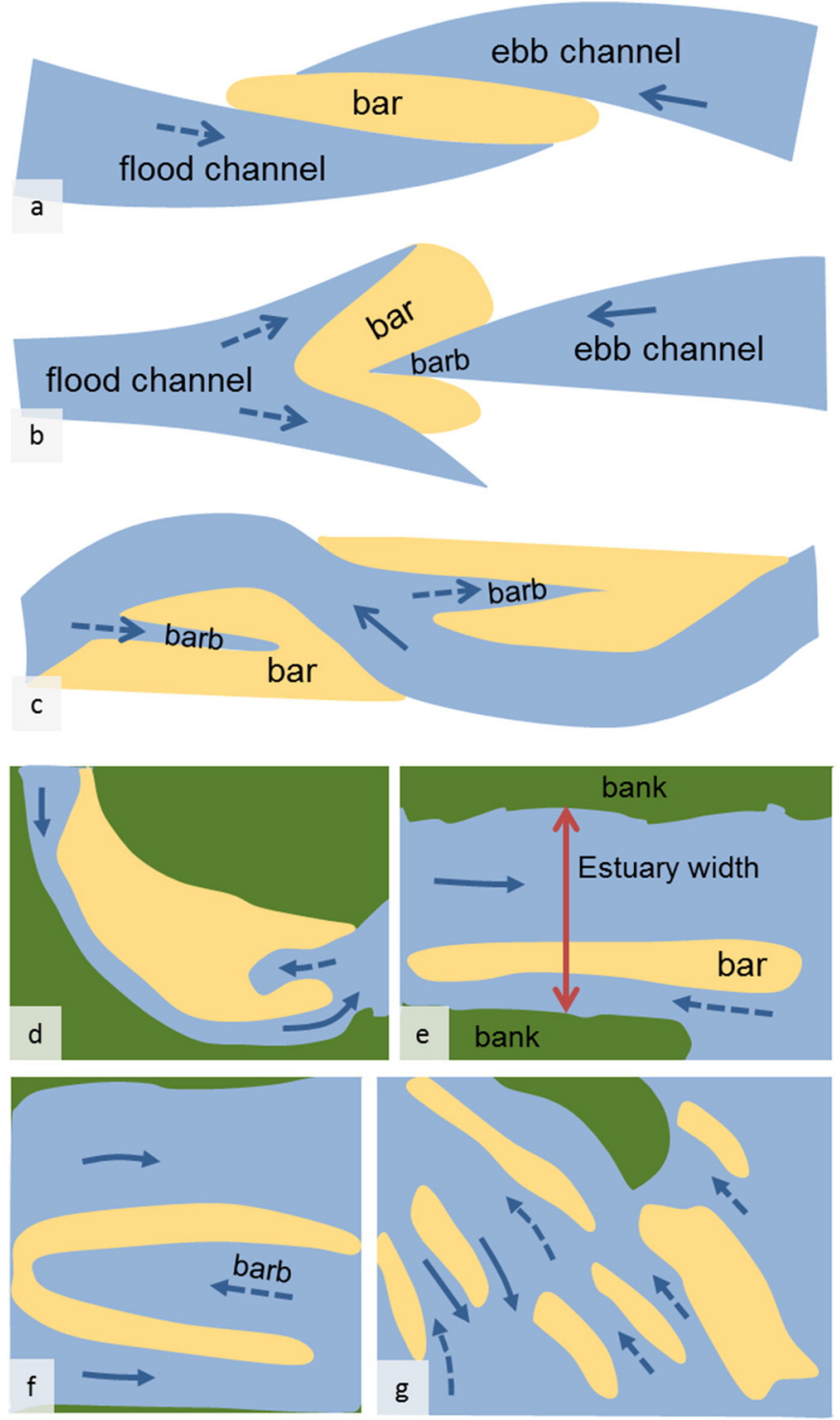

Fig. 3. Sketches of bar types recognised in literature. (a, b, c) Mutually evasive ebb- and flood-dominated channels separated by bars [after van Veen, 1950]; (d, e, f, g) Variation in the morphology of elongated sand bars in estuaries [after Dalrymple and Choi, 2007]. Solid arrows: ebb-dominated channels, dashed arrows: flood-dominated channels. 
generally have smaller dimensions than the main channel, but may enlarge over time, forming a chute channel (Bridge and Tye, 2000; Bridge, 2003; Sambrook Smith et al., 2006). For estuaries, Swinkels et al. (2009) described similar channels as smaller connecting channels that may increase or diminish over time.

The presence of mutually evasive ebb- and flood-dominated tidal channels is unique in tidal environments. These channels develop around the sand bars (van Veen, 1950; Dalrymple and Choi, 2007; Hibma et al., 2003; Kleinhans et al., 2015b). When they meet head-on, either they evade each other laterally (Fig. 3a,c,e,g) or one of the channels bifurcates and a u-shaped bar forms between the channels (Fig. $3 b, f)$. The tails of a u-shaped bar embrace a barb channel (Fig. 1e,f), which is a one-ended channel that partly crosscuts the bar and becomes shallower in the direction of flow (Dalrymple and Choi, 2007). Compound bars and side bars are often dissected by barb channels (Fig. $1 \mathrm{~h}$ ), while linear bars lack barb channels. Possible interpretations for barb channels are that they either form by the convergence of bedload around an initial bar core, as was previously described for rivers (Sambrook Smith et al., 2006), or that they are failed chute cutoff channels that are remnants of cross-bar channels, where successful chute cutoffs would increase the braiding index.

Dalrymple and Choi (2007) hypothesised that estuary width and curvature determine both the shape and the number of bars in crosssection, which is also expected by analogy with rivers (Kleinhans and van den Berg, 2011). Here, we define local estuary width as the width between the vegetated marshes or banks at the location of the measured bar, including the sand bars (see Fig. 1e). Only two analytical physics-based models are currently available for tidal systems. These theories predict bar length to increase with estuary width (Seminara and Tubino, 2001) or with flow velocity and tidal excursion length (Schramkowski et al., 2002), which is the distance that a water particle travels in half a tidal cycle. In contrast, theory for rivers predict bar properties to be mainly determined by channel width-to-depth ratio (see Kleinhans and van den Berg, 2011, for review). Toffolon and Crosato (2007) validated the prediction of braiding index of Seminara and Tubino (2001) for the Western Scheldt, which supported the earlier hypotheses that the braiding index increases with width-to-depth ratio. Numerical modelling showed that the braiding index and bar length scale with estuary width-to-depth ratio (Hibma et al., 2003). However, these hypotheses on sand bar properties in estuaries have not been validated against a larger set of field data. Therefore, we still lack a full explanation for the shapes and dimensions of bar patterns in natural estuaries. Moreover, a classification scheme for bar pattern in estuaries is absent, in contrast with bar patterns in river systems.

The objectives of this study are (1) to quantify bar shapes and dimensions in natural estuaries while accounting for water level effects on bar visibility on imagery, (2) to investigate relations between bar dimensions and hydrodynamic and geometrical properties of estuaries, and (3) to test physics-based bar theories.

This paper is organised as follows: first, we review bar theories for rivers and estuaries. Then we present data of 190 bars in 45 estuaries collected from imagery and explain methods of characterisation and analysis. We test effects of water level variation on emergent bar shape and pattern in bathymetric data of three cases. This is followed by discussion of our data compared to known river bar properties and possible applications of the novel empirical relations.

\section{Bar theory}

Stability analysis predicts the initial formation of bar patterns through a mathematical method to study wave lengths and migration of periodic patterns. It has proven to be a powerful technique with predictive capability used to gain basic understanding of the mechanisms causing such patterns and their dimensions. The stability models generally consist of a system of equations for momentum, continuity, sediment transport and bed evolution (Dodd et al., 2003). Simplification of the equations, because the nonlinear effects are ignored, allows an analytical solution that does not have the potential problems of numerical models, for instance when bars grow to amplitudes approaching the water depth (Dodd et al., 2003). Initial and boundary conditions are also simplified: bar theories used in this paper assume a long straight channel with constant width, non-erodible banks and an erodible sediment bed. However, despite such simplifications, stability analysis was successfully applied in many types of systems (Dodd et al., 2003), for example, river bars (Struiksma et al., 1985; Kleinhans and van den Berg, 2011), offshore sand ridges (Hulscher et al., 1993; Komarova and Hulscher, 2000), bedforms (Colombini, 2016) and sand waves (Blondeaux and Vittori, 2016). Part of what we know about river bars comes from these theories and given these past successes and that relatively little is known about tidal bars, it is of interest to test the few available theories for tidal bars. To set a frame of reference and link to the successful application in river bars that occur upstream of estuaries, we also include a theory for bars in rivers (Struiksma et al., 1985).

Our aim is to understand which factors influence bar patterns in the stability analyses and to obtain hypotheses for bar dimensions and braiding index in natural estuaries. Below, we first describe how linear stability analysis generally works in bar theory. Subsequently, we detail the main model components and compare the underlying assumptions. We show how the predicted bar dimensions and braiding index depend on the input parameters. After that, the results of all three theories are compared for a range of velocities $\left(0.5-2.0 \mathrm{~m} \mathrm{~s}^{-1}\right)$ and channel widths $(50-4000 \mathrm{~m})$ found frequently in nature. In a sensitivity analysis, we systematically vary model input for Struiksma et al. (1985) and Schramkowski et al. (2002), because only these theories were originally applied to the full range of channel widths that are considered in this study. For detailed descriptions of the model set-up or derivations of the solutions, the reader is referred to the original papers.

The models are applicable to converging estuaries despite the assumption of constant width because of what this assumption means in the context of linear stability theory. The stability analyses of Seminara and Tubino (2001) and Schramkowski et al. (2002) are local models, valid under the assumption that horizontal length scales are much smaller (i.e. an order of magnitude) than the length of the basin, the tidal wavelength, and the length scale of width variations of the basin (de Swart and Zimmerman, 2009). In other words, as long as the length scale of the tidal bars is much smaller than the length of estuaries and the tidal wavelength, and the channel width is not varying too abruptly due to constructions or geological constraints, bar patterns can be predicted for every point along an estuary, given the local geometry and set of flow conditions at that point. Model predictions are thus dependent on the local estuary width for which they predict bar pattern formation. Therefore this is how we applied the theory to natural systems: we use the measured estuary width at the measured bar location to predict the local bar pattern formation.

In all stability models, first the basic state is determined, which is a channel without any bar patterns (Dodd et al., 2003). Second, a small spatially periodic perturbation $\left(h^{\prime}\right)$ is applied to the bed, resulting in local water depth variations that represent the initial bars and channels (Fig. 4). The evolution of these patterns over time is determined. In linear stability analysis, it is assumed that the perturbation height $h^{\prime}$ is small with respect to the equilibrium water depth and is given by:

$h^{\prime}(x, y)=a_{h^{\prime}} e^{\omega t} \cos \left(\frac{2 \pi x}{L}\right) \cos \left(\frac{m \pi y}{W}\right)$

where $a_{h^{\prime}}$ is the amplitude of the perturbation, $L$ is the wave length of the perturbation and $L / 2$ is thus the bar length, $W$ is the width of the channel and $m$ is the cross-channel mode number. The growth rate of a perturbation $(\omega)$ is in principle a complex number, but it has only a real part in the studies discussed here. The growth rate $\omega$ determines whether the configuration with perturbations persists $(\omega=0)$, grows $(\omega>0)$ or disappears $(\omega<0)$ for fixed model parameters. For each 

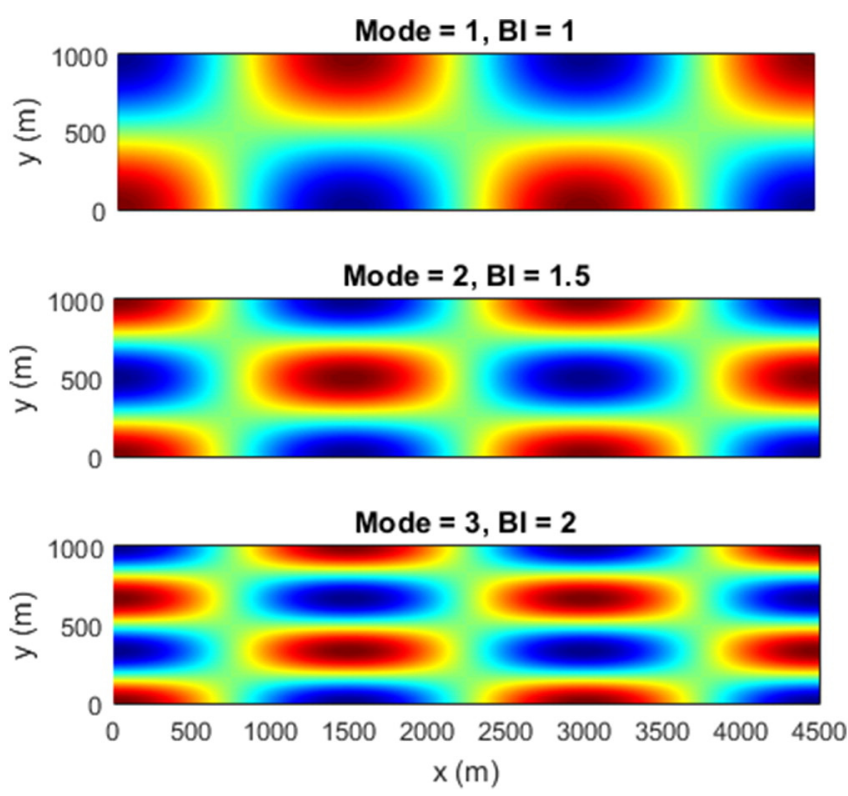

Fig. 4. Examples of the applied periodic perturbations, which in this case have the same wavelength and different cross-channel modes or braiding indices.

wave length $L$ and mode number $m$, the growth rate is determined. The configuration with the highest growth rate determines the dominant bar pattern, which is most likely to evolve in the river or estuarine channel. Bar mode relates to the braiding index $B I$ as

$B I \equiv \frac{m-1}{2}+1$

Here, we used the resulting analytical relations for Struiksma et al. (1985), the numerical solution for Schramkowski et al. (2002) and the data presented in Seminara and Tubino (2001, their Fig. 10).

\subsection{Theory for bars in rivers}

While many predictive theories for river bar dimensions are available (Schielen et al., 1993; Kleinhans and van den Berg, 2011), we limit our review to bar theory of Struiksma et al. (1985), which proved effective for a large dataset of various river patterns. On the basis of Struiksma et al. (1985), Crosato and Mosselman (2009) derived a predictor for bar length and braiding index. Struiksma et al. (1985) calculated the adaptation length of flow $\left(\lambda_{w}\right)$ and bed $\left(\lambda_{s}\right)$, where $\lambda_{w}$ is the longitudinal distance needed for the water to adapt to a perturbation of the bed and $\lambda_{s}$ is the longitudinal distance needed for the downstream bed to adapt to a forced upstream bed perturbation. The ratio $\lambda_{s} / \lambda_{w}$ predicts whether bars dampen out or excite (Crosato and Mosselman, 2009; Kleinhans and van den Berg, 2011). Crosato and Mosselman (2009) calculated that for the theory of Struiksma et al. (1985) the fastest growth rate $\omega$ occurs for:

$\frac{\lambda_{s}}{\lambda_{w}}=\frac{2}{(p-3)}$

where $p$ is the non-linearity of sediment transport ( $\mathrm{p}=4$ for sand) and $\lambda_{w}$ and $\lambda_{s}$ are given as:

$\lambda_{w}=\frac{1}{2} \frac{h}{c_{f}}$

$\lambda_{s}=\frac{h}{(m \pi)^{2}}\left(\frac{W}{h}\right)^{2} f(\theta)$ which is the equation by Struiksma et al. (1985), adapted for higher mode bars $(m>1)$ (see also Parker, 1976), in which the transverse bed slope function is given by

$f(\theta)=\frac{\theta^{m_{b s}}}{r_{b s}}$

with parameters $r_{b s}$ (typically 0.56 ) and $m_{b s}$ (typically 0.5 ). $\theta$ is defined as

$\theta=\frac{\tau_{n l}}{\left(\rho_{s}-\rho\right) g D_{50}}$

in which

$\tau_{n l}=\rho c_{f} \bar{u}|\bar{u}|$

where $\rho_{s}$ is the sediment density, $\rho$ is the water density, $h$ is the channel depth, $g$ is the gravitational constant, $D_{50}$ is the median grain size, $c_{f}$ is the friction coefficient, $\bar{u}$ is the depth-averaged river flow velocity, $|\bar{u}|$ the magnitude of the flow velocity and $\tau_{n l}$ is the non-linear bed shear stress. Sediment transport consists of only bed load transport with negligible sorting effects: the equation of Engelund and Hansen (1967) was used and adapted for bed slope effects.

Crosato and Mosselman (2009) reformulated the linear model of Struiksma et al. (1985) to directly define an estimator for the number of bars in cross section - rather than defining stable and unstable bar configurations as was previously done by Struiksma et al., 1985. They derived an expression for bar mode and bar length from Struiksma et al. (1985). The mode is given by the floor to the nearest integer of

$m=\frac{W}{h \pi} \sqrt{(p-3) f(\theta) c_{f}}$

The growing bed perturbation is harmonic in downstream direction (Crosato and Mosselman, 2009), which results in an equation for bar wavelength:

$L_{p}=\frac{4 \pi \lambda_{w}}{\sqrt{(p+1) \frac{\lambda_{w}}{\lambda_{s}}-\left(\frac{\lambda_{w}}{\lambda_{s}}\right)^{2}-\left(\frac{p-3}{2}\right)^{2}}}$

\subsection{Theory for bars in estuaries}

Seminara and Tubino (2001) used a linear 3-dimensional model, while Schramkowski et al. (2002) used a linearised 2-dimensional (depth-averaged) model for bars. Both studies prescribed $M_{2}$ tidal flow velocities and used a rigid lid approximation, which implies that only tide-induced flow velocities are taken into account while water level variations are neglected. In contrast with Seminara and Tubino (2001), Schramkowski et al. (2002) retained local inertia terms in the momentum equations. The bottom was considered time independent for timescales on the order of a tidal period. Seminara and Tubino (2001) used the same expression for bed shear stress as Struiksma et al. (1985) (Eq. (8)). Bed shear stress was linearised in Schramkowski et al. (2002), such that the amount of dissipated energy by friction during a tidal cycle is equal to the situation with non-linear bottom friction:

$\tau_{\text {lin }}=\rho\left[\frac{8}{3 \pi} c_{f} U\right]|\overline{u(t)}|$

where $U$ is a typical magnitude of flow velocity, assumed to be constant (typically $1 \mathrm{~m} \mathrm{~s}^{-1}$ ) and $|\overline{u(t)}|$ is the tidal flow velocity over time.

Sediment transport consists of both bed-load and suspended-load transport in Seminara and Tubino (2001). In contrast, Schramkowski et al. (2002) only used the bed slope induced part of the bed-load 
transport $\left(S_{b, S C}\right)$ and calculated suspended load transport. In Seminara and Tubino (2001), bed-load transport was calculated with the MeyerPeter and Müller (1948) equation and adapted for bed slope effects:

$\overrightarrow{Q_{b, S T}}=\overrightarrow{Q_{b, c u r}}+\overrightarrow{Q_{b, b s l}}$

in which $Q_{b, c u r}$ is the tidal current induced transport and $Q_{b, b s}$ is bed slope induced, defined as

$\overrightarrow{Q_{b, c u r}}=8\left(\theta^{\prime}-\theta_{c}\right)^{1.5} \sqrt{\operatorname{Rg} D_{50}{ }^{3}}$

$\overrightarrow{Q_{b, b s l}}=-\overrightarrow{Q_{b, c u r}} \frac{W}{2 h} \frac{r_{b s}}{\theta^{m_{b s}}}\left(0, \frac{\partial h}{\partial y}\right)$

where $R$ is the relative submerged density and $\frac{\partial h}{\partial y}$ is the transverse bed slope. See Seminara and Tubino (2001) for constitutive equations for $\theta^{\prime}$ and $\theta_{c}$. Shear stress is calculated from flow velocity and skin friction (van Rijn, 1984). For bed-load transport, Schramkowski et al. (2002) only used the part that accounts for the bed slope effect:

$\overrightarrow{Q_{b, S C}}=-\overrightarrow{Q_{b, c u r}} \frac{W}{2 h} \frac{r_{b s}}{\theta^{m_{b s}}}\left(\frac{\partial h}{\partial x}, \frac{\partial h}{\partial y}\right)$

in which $\frac{\partial h}{\partial x}$ is the along-channel bed slope. Bed slope transport was independent of flow conditions and channel geometry in Schramkowski et al. (2002) and set to a constant value $\lambda$. For comparison (Section 2.3), we tuned $\lambda$ such that the bed slope effect is equal at peak tidal velocity for both theories.

For suspended load, Schramkowski et al. (2002) used the advectiondiffusion equation of van Rijn (1993):

$C_{t}+\left(u C-\mu C_{x}\right)_{x}+\left(v C-\mu C_{y}\right)_{y}=S \equiv \alpha\left(u^{2}+v^{2}\right)-\gamma C$

where $C$ is the volumetric depth-integrated concentration $\left[\mathrm{m}^{3} / \mathrm{m}^{3}\right], \mu$ is the horizontal coefficient for sediment diffusion, $S$ is erosion minus sedimentation, $\alpha$ is an erosion constant (typically $10^{-5} \mathrm{~s} \mathrm{~m}^{-1}$ ). The settling parameter $\gamma$ is equal to $w_{s}^{2} / k_{v}$, in which $w_{s}$ is the settling velocity (typically $10^{-2} \mathrm{~m} \mathrm{~s}^{-1}$ ) and $k_{v}$ is the depth-averaged vertical eddy diffusivity (typically $0.09 \mathrm{~m}^{2} \mathrm{~s}^{-1}$ ). Seminara and Tubino (2001) used a similar time-dependent equation for sediment concentration in 3D in which horizontal dispersion is neglected. The major difference between Seminara and Tubino (2001) and Schramkowski et al. (2002) is the formulation of the sediment entrainment. In Seminara and Tubino (2001), $S$ is proportional to the difference between the local sediment concentration and the near-bed concentration at equilibrium $\left(C_{e q}\right.$ in $\left.\left[\mathrm{m}^{3} / \mathrm{m}^{3}\right]\right)$ with the local flow. The equilibrium concentration is calculated with van Rijn (1984):

$C_{e q}=0.015 \frac{D_{50}}{0.01 h}\left(\frac{\theta^{\prime}}{\theta_{c}-1}\right)^{1.5} R_{p}^{-0.3}$

where $R_{p}$ is the Reynolds particle number, which is given as:

$R_{p}=\sqrt{\frac{\operatorname{Rg} D_{50}{ }^{3}}{\nu}}$

where $v$ is the kinematic viscosity.

\subsection{Comparison}

For a fair comparison between Seminara and Tubino (2001) and Schramkowski et al. (2002), it is necessary to determine the value of the settling parameter $(\gamma)$ and the erosion constant $(\alpha)$ for which the sediment concentration is equal in both models. For $\gamma$, we used the depth-averaged eddy diffusivity $\left(k_{v}\right)$ of Seminara and Tubino (2001) and a constant settling velocity. Subsequently, $\alpha$ was chosen such that the model is in morphological equilibrium for a steady flow $(S=0$ in Eq. (16)):

$\alpha=\frac{\gamma C}{u^{2}}$

where $C$ is the depth-integrated sediment concentration over depth $h$ of Schramkowski et al. (2002) for a certain flow velocity, given by

$C=\int_{0}^{h} C_{z} d z=\int_{0}^{h} C_{e q} \exp \left(\frac{-w_{s}}{k_{v}} z\right) d z$

where $C_{e q}$ is the near bed sediment concentration of Seminara and Tubino (2001) given by Eq. (17).

Bar width was in all cases determined as half the estuary width divided by the braiding index. Furthermore, it should be remarked that flow velocity for river models is constant and unidirectional while the indicated flow velocity for estuaries is a peak velocity and bidirectional.

We calculated the maximum growth rate of perturbations for the theory of Schramkowski et al. (2002) (SC) and compared this with the results of Seminara and Tubino (2001) (ST) and the predictor derived from Struiksma et al. (1985) by Crosato and Mosselman (2009) (CM). We varied the flow velocities in CM and the amplitude of tidal flow velocity in SC from $0.5-2.0 \mathrm{~m} \mathrm{~s}^{-1}$ and applied channel widths varying from $50-2000 \mathrm{~m}$. The default parameters of ST were used for comparison (Table 1 ).

The most important result is that bar length depends mainly on the amplitude of tidal flow velocity in SC and ST, while in river theory it also depends on river width (Fig. 5). All theories predict bar length in the same order of magnitude for systems with the same width and amplitude of tidal flow velocity (Fig. 6). CM predicts bar lengths a factor 3 larger than tidal theory for small channels. For wide channels $\left(>10^{3} \mathrm{~m}\right)$, bar wavelength becomes independent of increasing braiding index (Fig. 5a,c).

Bar width increases with estuary width for all theories. When the estuary width exceeds the threshold for a higher bar mode, bar width reduces (Fig. 5). Predicted bar widths are 3-40 times shorter than bar length (Fig. 5).

The braiding index increases with estuary width and width-todepth ratio (Fig. 5c,f) for SC and CM. For narrow channels, the braiding index is 1 , which is the alternate bar mode. For wide channels, the braiding index increases with higher flow velocities and sediment mobility (Fig. 5c,f). When a higher bar mode excites, bar length reduces until the channel width is further increased.

Concluding, SC and ST predict that bar length increases with flow velocity, thus tidal excursion length. Channel geometry determines the braiding index, with higher braiding indices for wider channels. Theory also implies that relatively long and narrow bars form under high flow

Table 1

The values Default were used in the comparison of bar theory and sensitivity analysis. Values are based on the defaults of Seminara and Tubino, 2001. Range indicates the range over which was varied in the sensitivity analysis. Tidal frequency is not applicable in the case of river theory.

\begin{tabular}{lllll}
\hline Name & Symbol & Default & Range & Unit \\
\hline Non-linearity sed. transport & $\mathrm{n}$ & 4 & & - \\
Friction coefficient & $c_{f}$ & $2.5 \cdot 10^{-3}$ & $0.6-10 \cdot 10^{-3}$ & - \\
Density sediment & $\rho_{s}$ & 2650 & & $\mathrm{~kg} \mathrm{~m}^{-3}$ \\
Density water & $\rho$ & 1000 & & $\mathrm{~kg} \mathrm{~m}^{-3}$ \\
Median grain size & $D_{50}$ & $1 \cdot 10^{-4}$ & $0.25-4 \cdot 10^{-4}$ & $\mathrm{~m}^{2}$ \\
Kinematic viscosity & $\nu$ & $1 \cdot 10^{-6}$ & & $\mathrm{~m}^{2} \mathrm{~s}^{-1}$ \\
Eddy diffusivity & $k_{v}$ & 0.09 & & $\mathrm{~m}^{2} \mathrm{~s}^{-1}$ \\
Settling velocity & $w_{s}$ & $1 \cdot 10^{-2}$ & Varied with $D_{50}$ & $\mathrm{~m} \mathrm{~s}^{-1}$ \\
Tidal frequency & $\sigma$ & $1.4 \cdot 10^{-4}$ & $0.35-5.6 \cdot 10^{-4}$ & $\mathrm{~s}^{-1}$ \\
Bed slope parameter & $r_{b s}$ & 0.56 & $0.14-2.24$ & - \\
Bed slope parameter & $m_{b s}$ & 0.5 & & - \\
Water depth & $h$ & 5 & $2.5-40$ & $\mathrm{~m}$ \\
Erosion constant & $\alpha$ & $1 \cdot 10^{-5}$ & & $\mathrm{~s} \mathrm{~m}$ \\
Estuary/river width & $W$ & 1000 & $50-4000$ & $\mathrm{~m}^{-1}$ \\
\hline
\end{tabular}



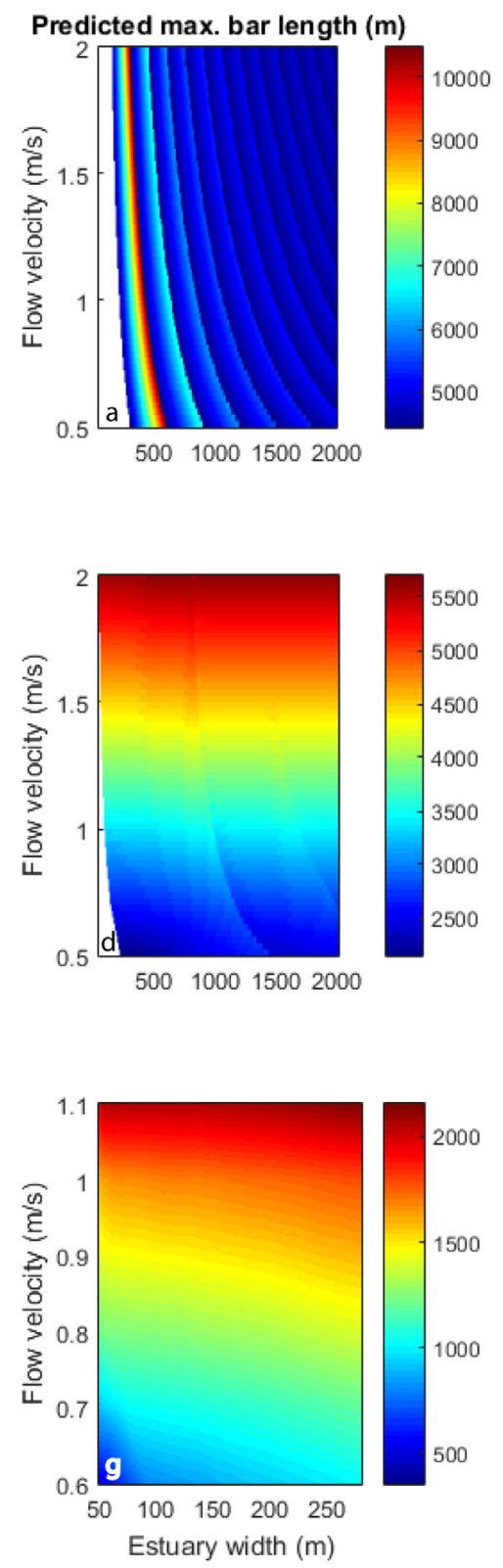
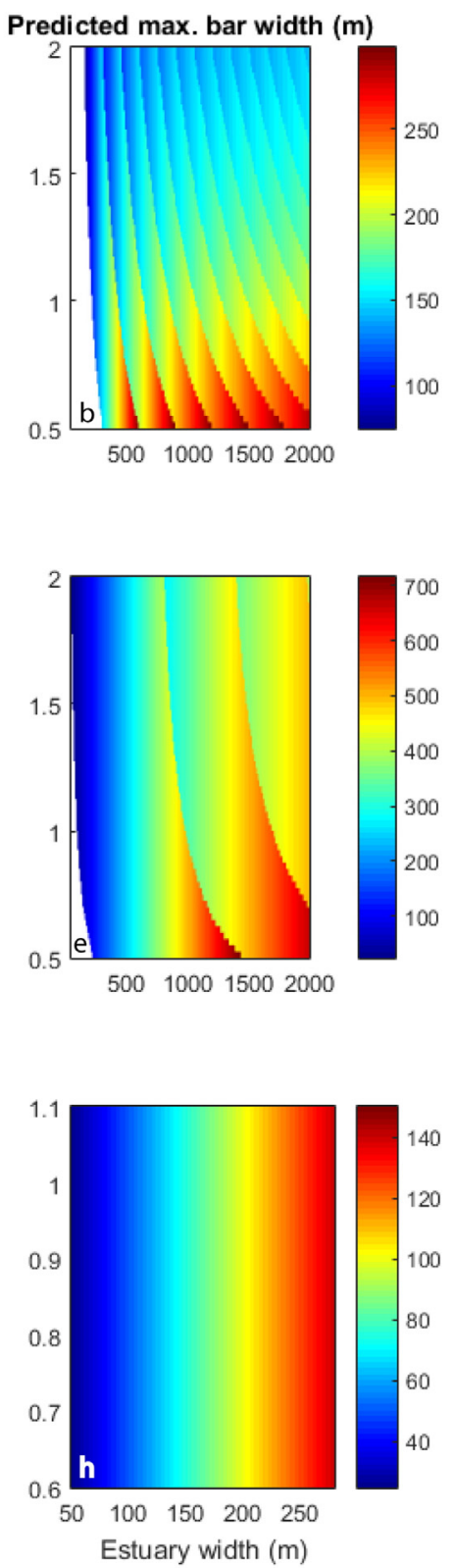
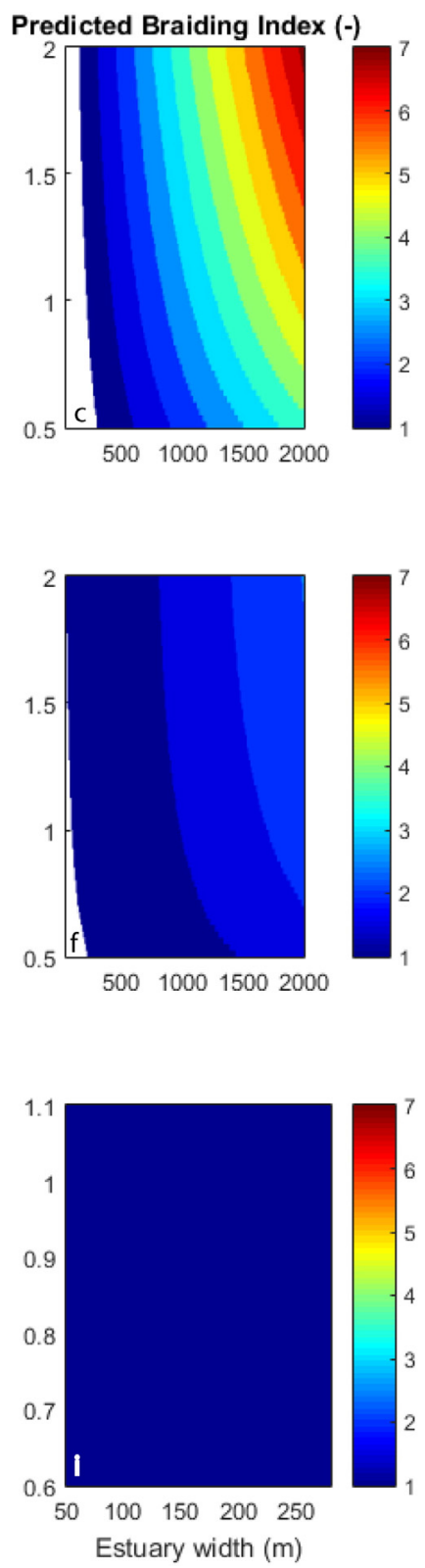

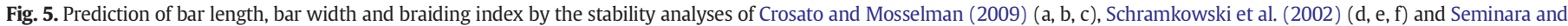
Tubino (2001) (g, h, i). Note that the scale of colour bars differs between theories and the range of channel widths shown for Seminara and Tubino (2001) is smaller.

velocities in narrow channels, while wide and shorter bars form in wide channels with low flow velocities. These results are partly in contrast with the hypothesis of Dalrymple and Choi (2007) and river theory that bar dimensions and braiding index relate to channel width. The theoretical models described here are compared with data of natural estuaries in Section 4.4 .

\subsection{Sensitivity analysis}

The default values and the range of varied values for the sensitivity analysis are given in Table 1. In the comparison, we calculated erosion constant $\alpha$ based on equal sediment concentrations in Seminara and Tubino (2001) and Schramkowski et al. (2002). In the sensitivity analysis, we set $\alpha$ to the default constant of Schramkowski et al. (2002), which is $10^{-5}$ [ $\mathrm{s} \mathrm{m}^{-1}$ ].

The sensitivity analysis shows that predicted bar length and braiding index are most sensitive to friction $\left(c_{f}\right)$ and channel geometry. Larger friction increases braiding index and decreases bar length (Fig. 7a,b).
Increasing grain size $\left(D_{50}\right)$, and coupled increasing settling velocity, results in lower braiding indices and shorter bars (Fig. 7e,f). For SC, the braiding index remains constant and the only effect is a decrease in bar length (Fig. 7e,f). $D_{50}$ mainly influences bed slope effect in $C M$, which may explain a similar trend in sensitivity to $D_{50}$ as to bed slope parameter r. Increasing bed slope effect reduces the braiding index, while bar length remains in the same order of magnitude (Fig. 7i,j). When the braiding index shifts towards a lower value, bar length increases. For constant braiding index and increasing bed slope effect, bar length decreases.

We varied width-to-depth (aspect) ratio in three manners: (1) by increasing channel depth while keeping width constant (Fig. 7c,d), (2) by increasing width with constant depth (Fig. 7g,h) and (3) by increasing width and depth according to the width and depth ratios found in natural estuaries (Fig. $7 \mathrm{~m}, \mathrm{n}$ ):

$$
h=2.27 W^{0.2}
$$



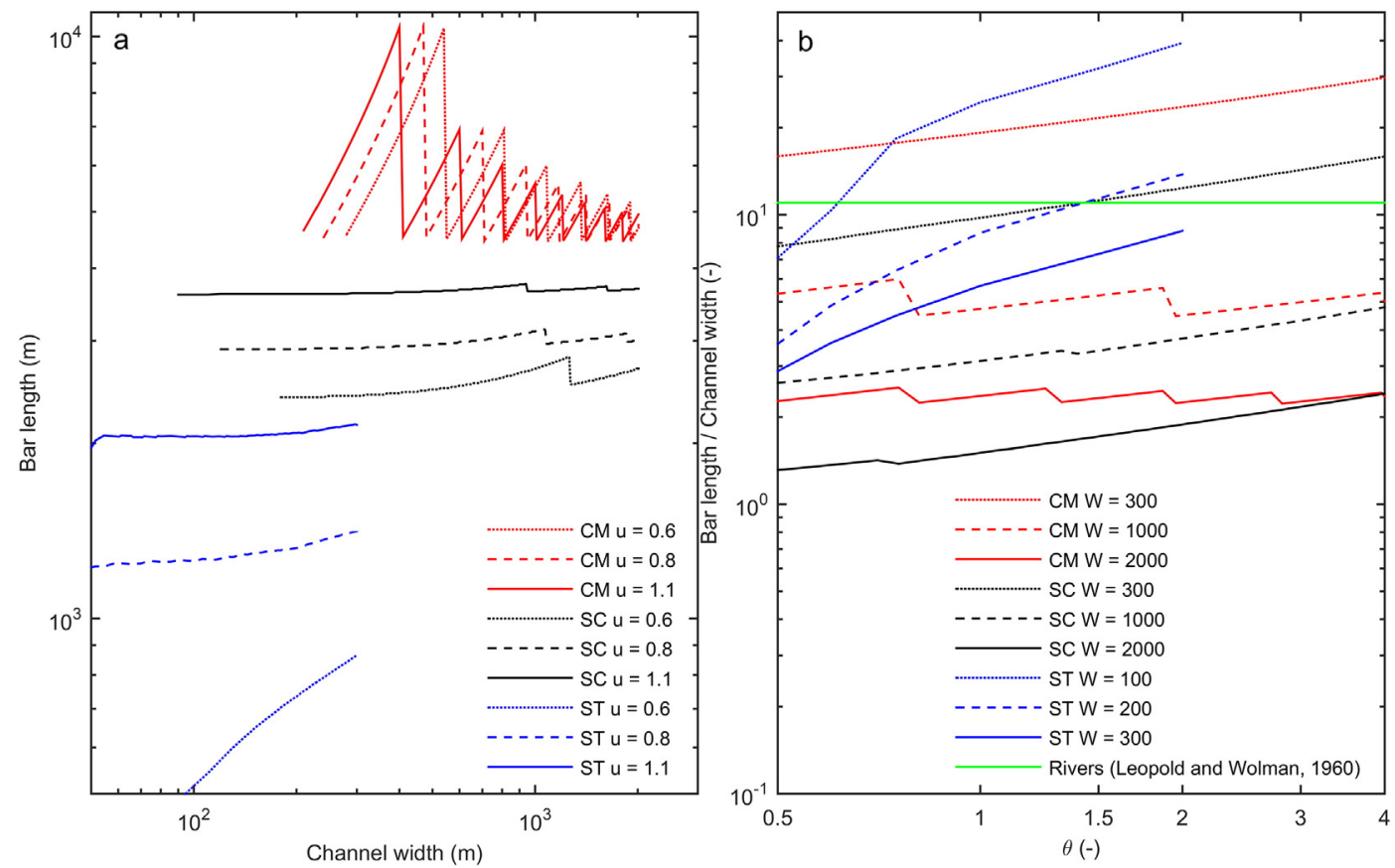

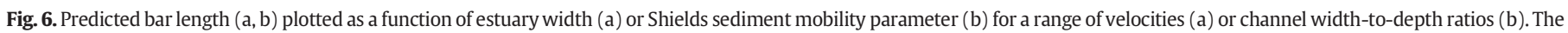
ratio between bar length and channel width for rivers (Leopold and Wolman, 1960) is drawn for comparison.

Here, we used an estimation of the width-averaged estuary depth and the measured local estuary width of the natural estuaries in our dataset as described in Section 3.2. The data are given in the Supplementary material. Fig. A.17c shows the data used for this regression. The goodness of fit $\left(R^{2}=0.17\right)$ is sufficient for the purpose of a sensitivity analysis, but explains only part of the variance in estuary geometry as indicated by the confidence limits that plot approximately a factor 3 above and below the regression (Fig. A.17c).

Increasing the aspect ratio results in all cases in higher braiding indices. The braiding index decreases to 1 when width is fixed and depth is increased (Fig. 7d). Similarly, the braiding index is very sensitive to increasing width when depth is constant (Fig. 7h). When width and depth are coupled (Eq. (21)), the braiding index still increases with larger aspect ratios (Fig. 7n). Bar length increases with increasing depth (Fig. 7c).

Tidal period and tidal current velocity both influence the tidal excursion length. Therefore, we assessed the sensitivity to tidal period and current velocity in two ways (Fig. 7k,l,o,p). The dashed lines in Fig. 7k,1,o,p show the cases for which either tidal period or current velocity was varied, thus allowing the tidal excursion length to vary. In the other cases, a change in tidal period was compensated by an opposite change in current velocity in order to exclude the possible effect of varying tidal excursion length (solid lines in Fig. 7k,l,o,p). Increasing tidal current velocities resulted in lower braiding indices and longer bars in all the cases mentioned above. This includes the cases where tidal excursion length was kept constant by decreasing tidal period when tidal current increased (Fig. 7k,1,o,p). Braiding index was insensitive to tidal period (Fig. 7p). Increasing the tidal excursion length by increasing the tidal period only resulted in longer bars when tidal current velocity was kept constant (Fig. 7o). Therefore, we concluded that bar dimensions are determined by tidal current velocity rather than tidal excursion length.

\section{Data collection}

\subsection{Selection of estuaries}

Satellite imagery was used to measure the shapes and dimensions of 190 bars in 45 estuaries all over the world (see Appendix A). We selected 45 funnel shaped alluvial estuaries with substantial tidal sand bars in order to be able to visually measure bar dimension from aerial images. Ideally, only laterally unconstrained estuaries sensu Townend (2012) would have been selected, analogous to the approach for rivers of Kleinhans and van den Berg (2011), excluding estuaries confined by geology, dams, groynes, artificial cutoffs or other local human interference. However, the sparsity of data on the hydrological and physical properties forced us to select the estuaries for which data were available. The dataset includes some estuaries with local constrains by human interference or by bedrock geology. In these cases, it was recorded in the dataset (see Appendix B). In addition, the presence of vegetation and the climate were recorded. All estuaries, except one, were located in temperate climate. Vegetation was present on 29 out of 190 tidal bars.

\subsection{Data collection}

Based on Google Earth images (accessed May-September 2015), we classified 190 bars and measured their dimensions. We used four classes: linear, u-shaped, compound and sidebars. The former three classes were in most cases completely surrounded by water, whereas sidebars were not. Bars were classified as sidebars if the length over which the bar was connected to the side of the estuary was larger than the bar width. Long bars with a relatively small width were classified as linear. The compound class was assigned when the bar was neither linear nor u-shaped (for examples, see Figs. 1 and 3).

For all bars we measured maximum bar length $(l)$, maximum bar width $(w)$, perimeter and surface area (Fig. 9). Furthermore, we recorded the along-channel distance from the estuary mouth, the local width $(W)$ of the estuary and the local braiding index (BI). In this study, local estuary width is defined as the width between the vegetated marshes or banks at the location of the measured bar including the sand bars. Moreover, we used this definition, because the timescale over which tidal marshes form is much larger than the timescale for the morphodynamic equilibrium of the bars in cross-section of the estuary (Kleinhans et al., 2015a). Measured local width is thus independent of the tidal elevation. On the other hand, measurements of individual bars were dependent on tidal elevation.

Bars were generally measured from aerial photographs between mean sea level (MSL) and low water level (LWL). The precise water 
level with respect to mean sea level was unknown for the moment at which an aerial photograph was taken. To investigate the likely measurement error arising from the unknown flow stage, we quantified the possible error for individual bars using high-resolution bathymetries of three estuaries. The following estuaries were used: Western Scheldt (NL), Dovey estuary (Wales) and Broad River estuary (USA). Within each estuary, hypsometric curves were calculated for four bars that were surrounded by channels and troughs. The root of the total area above a given elevation was used to obtain a characteristic measurement of length for each bar (Fig. 8a). We calculated the typical measurement of length for each bar at the water level exactly between MSL and LWL (Fig. 8b). The deviation of measurements taken at MSL or at LWL from the typical measurement of area $^{0.5}$ gave the uncertainty in bar measurements (Fig. 8c).

Bar height was measured in the three estuaries for which high-resolution bathymetry was available and eight additional estuaries in the UK for which lidar data are available from the UK government. These additional estuaries could not be used to study the sensitivity to water level variations, since accurate lidar data often do not extend to larger water depths. We calculated the total bar height $\left(h_{\text {bar }}\right)$ as the sum of channel depth and bar height above mean sea level for the estuaries for which bathymetry was available. Channel depth was defined as the average local depth below mean sea level. Furthermore, we recorded the standard deviation of bar height above mean sea level.
Hydrological and physical properties were retrieved from the Enhanced UK Estuaries database (Manning, 2007), the National Estuarine Eutrophication Assessment Estuaries Database (USA, ian.umces.edu/ neea), National Ocean Service's Estuarine Bathymetry (USA, estuarinebathymetry.noaa.gov) and in some cases specific data from a case study (Dalrymple et al., 1990; Jeuken et al., 2003; Billy et al., 2012; Wolanski, 2014; Alam et al., 2014). These data include typical flow velocities and estimates of tidal prism. In case of the UK Estuaries database, estimates of tidal prism were based on approximate measurements of high water volume and low water volume (Townend, 2005; Manning, 2007). Townend (2005) assessed the likely error arising from their approach and found that tidal prism is on average overestimated by $30 \%$. Bathymetry and lidar data were obtained from Rijkswaterstaat (NL), Aberystwyth University (Wales) and the National Ocean Service's Estuarine Bathymetry (USA).

\subsection{Data processing}

Only the non-amalgamated bars should be compared with the predictions from linear stability analyses. Therefore, measured bar widths were partitioned by the number of barb channels that intersect the bar (Fig. 9). The barbs are traces of the amalgamation or incipient splitting of bars. In the framework of the theoretical approach (Fig. 4), both sedimentary and erosional mechanisms are indicative of the natural
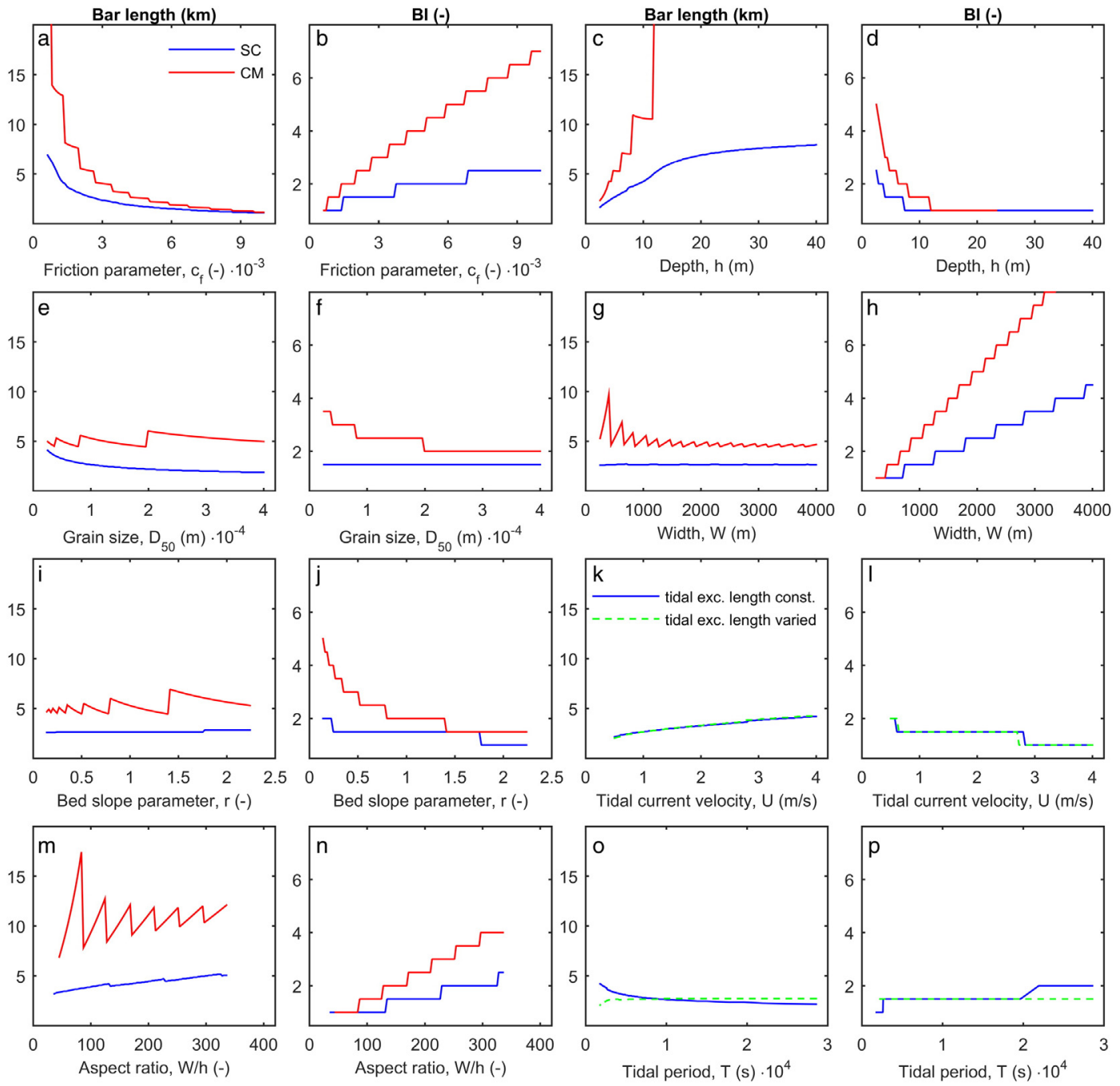

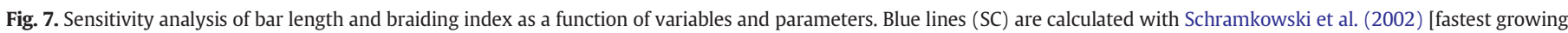
configuration in Eq. (1)] and red lines (CM) are calculated with Struiksma et al. (1985) with the braiding index derived by Crosato and Mosselman (2009) [Eqs. (9)-(10)]. 

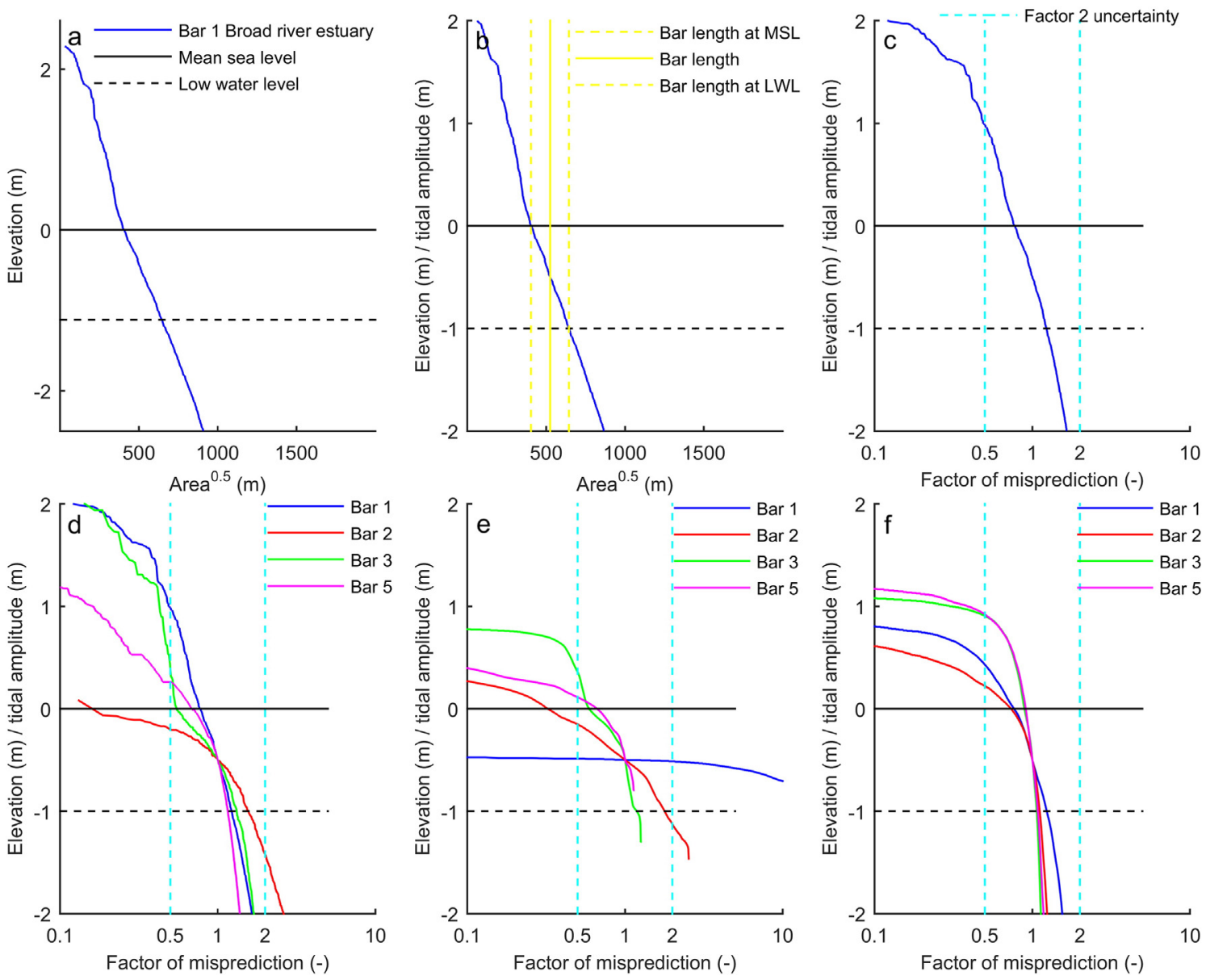

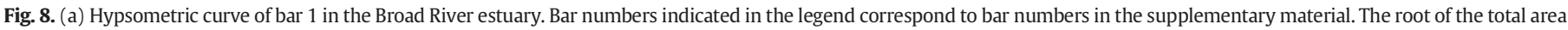

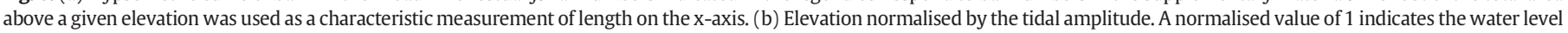

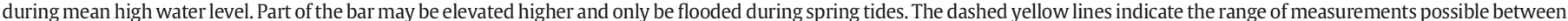

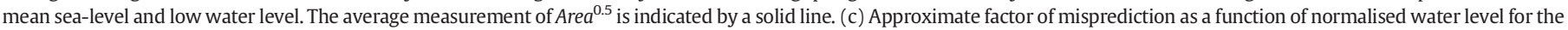

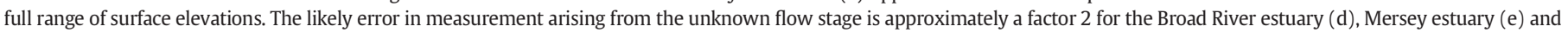
Western Scheldt (f).

braiding index that develops in a system. Schuurman et al. (2013) showed that theory predicted the length of amalgamated bars well, but overpredicted the braiding index in case of unpartitioned amalgamated bars. Therefore, we divided the maximum width of side bars and compound bars by the sum of intersecting and surrounding channels (Fig. 9). Similarly, for u-shaped bars this means dividing the maximum measured width by 2 (Fig. 9). We calculated the partitioned bar width $\left(w_{p}\right)$ as:

$w_{p}=\frac{w}{(c-1)+b+s}$

where $c$ is the number of surrounding channels, $b$ is the number of barb channels and $s$ is 1 in case the bar type is sidebar and 0 in all other cases.

Based on the bar location, we estimated the bar specific or local tidal prism, which is the total volume of water passing the tidal bar over half a tidal cycle. To obtain this, the approximate surface area upstream of the bar location was calculated and divided by the total surface area of the estuary. Consequently, the multiplication of this factor with the total tidal prism gave a bar specific estimate of the tidal prism.

For cases without bathymetry, we estimated width-averaged estuary depth at the bar locations. Savenije (2015) found that the depth along 28 estuaries often show a linear or almost linear profile. This is evidence that a linear interpolation between estuary mouth and upstream river is a reasonable estimate and in this case the only possible estimate for lack of data. Depth at the estuary mouth was available in the
Enhanced UK Estuaries database (Manning, 2007) and depth at the mouth was measured from bathymetry when available. Other estuaries were left out this analysis. River depth was calculated based on hydraulic geometry for rivers (Leopold and Maddock, 1953; Hey and Thorne, 1986):

$h=b Q^{q}$

where $Q$ is the river discharge and $b$ and $q$ are constants, where $b$ is 0.33 and $q$ is 0.35 . $Q$ was derived from the databases mentioned above. Measured estuary depth at bar locations was compared with the estimated depth, which showed that all predictions are within a range of $10 \%$ from the measured value. The Western Scheldt was an exception, with channels being $50 \%$ deeper than predicted as a result of the dredging activities. Given the difficulties and uncertainties in the prediction of estuary depth (Gisen and Savenije, 2015; Savenije, 2015) and the lack of detailed data on estuarine geometry, our approach seems a reasonable first step to assess whether a relation between bar dimensions and estuary depth may exist.

In the results section, regressions and confidence limits are given for the presented relations. Linear regressions were calculated minimising the residuals in both the $\mathrm{x}$ - and $\mathrm{y}$-directions, which it is the most robust and conservative method. Confidence limits are given for two standard deviations from the regression. The legends show the approximate multiplication factor that the confidence limits plot higher or lower than the trend. 

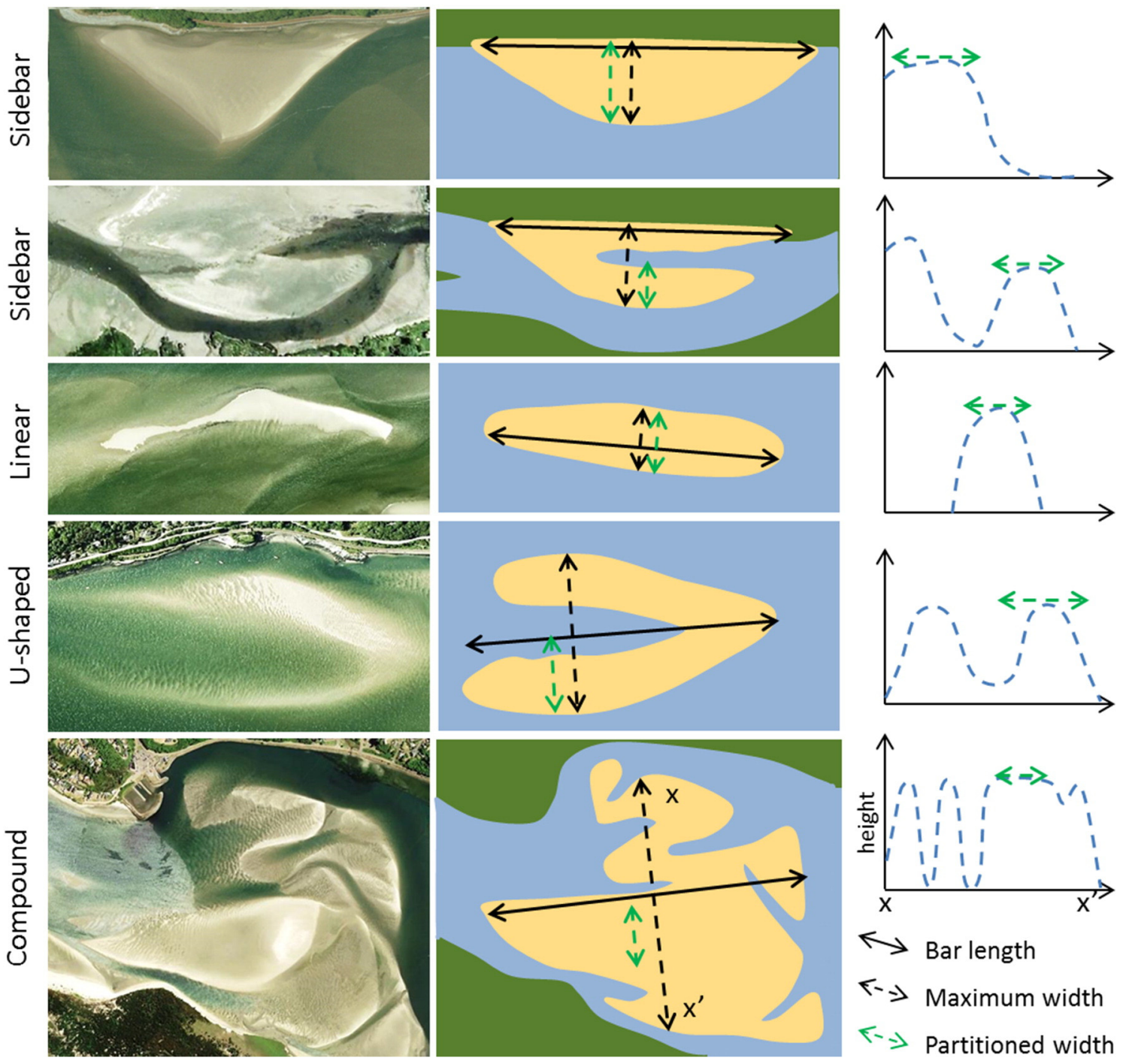

$\longleftrightarrow$ Bar length

$\leftrightarrow$ Maximum width

$r$ Partitioned width

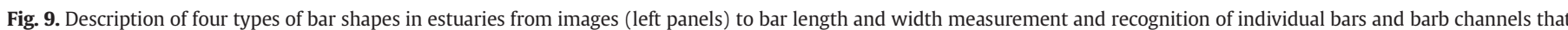
compose the bar complex in planform (middle panels) and cross-section (right panels). Partitioned bar width was calculated with Eq. (22).

\section{Results}

In this section, we first present empirical relations between bar length, width and height. Then we explore relations between bar dimensions and braiding index with hydrodynamic and geometrical properties of the estuaries. From bathymetric data we check effects of water level variations on bar shape and braiding index. Subsequently, the theoretical models are compared with the data. Fig. A.17 shows the hydraulic geometry relations in the dataset.

\subsection{Bar shapes and dimensions}

We visually classified four different types of bars based on their shape and connection with the estuary banks or marshes: linear, ushaped, side- and compound bars. All bar types occur for the full range of measured dimensions: $50-30,000 \mathrm{~m}$ long and 20-20,000 m wide (Fig. 10a). Width-to-length ratio relates to bar type: linear bars are generally 3 to 15 times longer than their width, while u-shaped and compound bars are more circular or square with bar lengths of 1 to 5 times their width (Fig. 10a). Sidebars occur in width-to-length ratios of 1 to 15 .
Fig. 10b shows that the range of width-to-length ratios narrows considerably when partitioned bar width is used. As a result of the similarity collapse, the range of all width-to-length ratios is equal to the dimensions found for linear sand bars:

$l=6.9 w_{p}$

which is valid over more than two orders of magnitude (Fig. 10b). The similarity collapse supports the hypothesis that the amalgamation or incipient splitting of bars can be used to partition compound bars. A similar relation was found by (Kelly, 2006) for braided rivers:

$l=4.95 w^{0.97}$

This implies that all bar classes in estuaries have approximately the same shape as river bars after partitioning, with sand bars in estuaries being on average slightly longer $\left(6.9 w_{p}\right)$ than river bars $(4.95 w)$.

Fig. 11a,b shows that bar dimensions appear to be interrelated. We found that bar length could be predicted within a factor 5 when bar height is known (Fig. 11b). The goodness of fit for bar width as a function of bar height is much lower and the scatter is larger (Fig. 11a). 


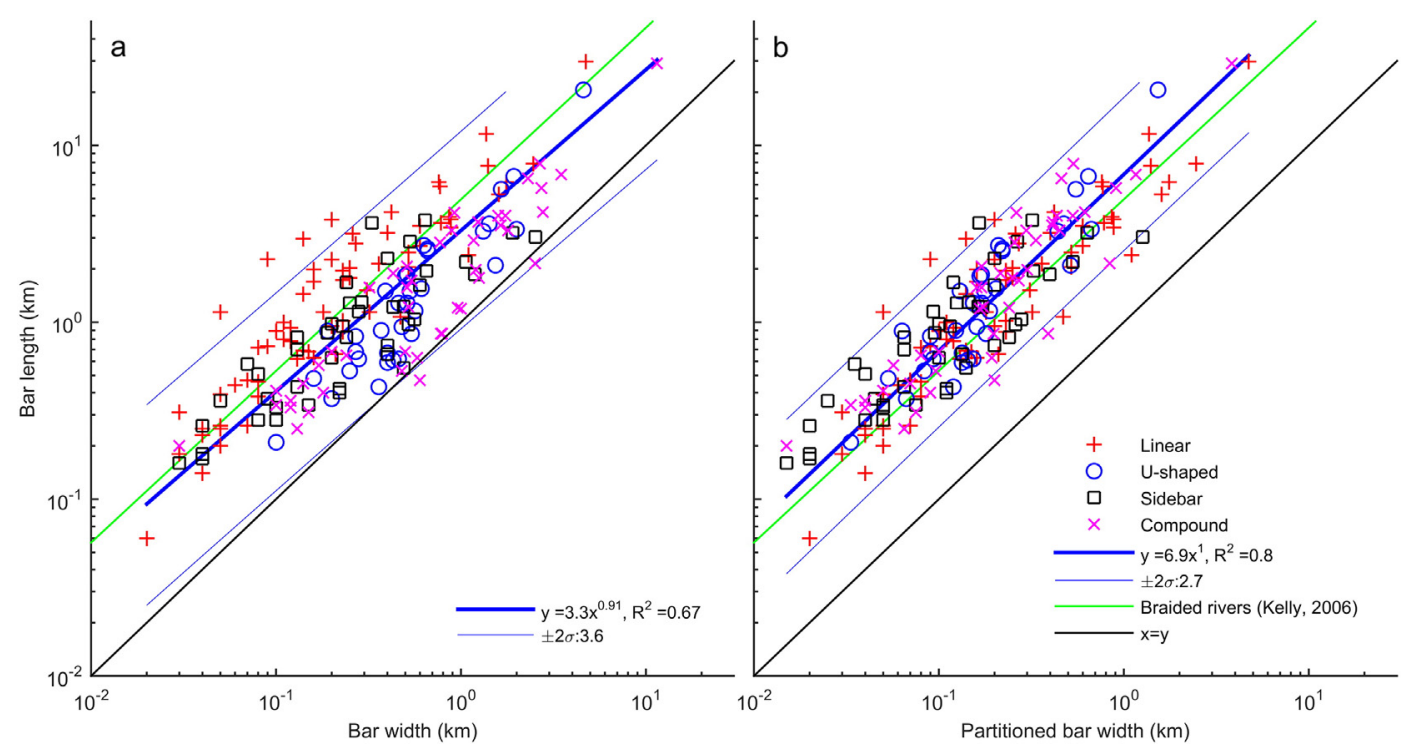

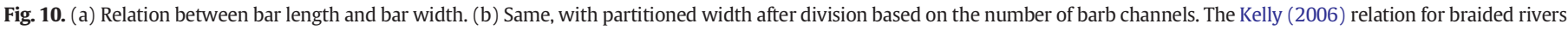

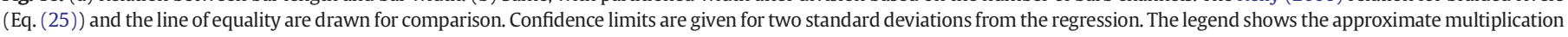
factor that the confidence limits plot higher or lower than the trend.

The three-dimensional shape of bars in estuaries is best characterised with half an ellipsoid (Fig. 11c). This results from calculations of bar volume $(V)$, based on measurements of length $(l)$, width $\left(w_{p}\right)$ and height $\left(h_{\text {bar }}\right)$ :

$\frac{1}{2} \cdot V_{\text {ellipsoid }}=\frac{1}{6} \pi l w_{p} h_{\text {bar }}$

Calculating bar volume as a square box would lead to an overprediction of bar volume, while adapting the shape of half a cylinder would lead to an underprediction. However, when the ellipsoid is used as a characteristic shape, the calculated bar volume predicts bar volume well within a factor three (Fig. 11d). Either bar length, width or height could be used to predict bar volumes (Fig. 11e,f). The prediction is most accurate when bar length is used:

$V=0.08 l^{2.3}$

We found that u-shaped bars form in both ebb and flood directions and that linear and compound bars have often steep edges on both their seaward and landward side. Ebb- and flood-dominated currents typically produce mutually evasive tidal channels (van Veen, 1950; Kleinhans et al., 2015b) that often end in barb channels. Most of these features seem to be unique for tidal environments, which raises the question: to what extent are the forming mechanisms of bars in estuaries similar to the mechanisms that form bars in rivers?

\subsection{Relation between bar dimensions and estuarine properties}

In general, we found that bar dimensions scale with estuary dimensions, in particular with width and depth. Bars are clearly longer in wider estuaries and in higher tidal current velocities (Fig. 12a). Bar length varies from 3 times smaller to 3 times larger than the estuary width (Fig. 12c). Part of this spread is the result of two trends. First, bar length normalised with estuary width decreases with estuary width-to-depth (aspect) ratio, where bar length equals estuary width for an aspect ratio of about 200 (Fig. 12e). Second, bar length is largest for higher tidal current velocities (Fig. 12a,d). Nevertheless, bar length is independent of tidal current in the range of 0.8 to $1.2 \mathrm{~m} \mathrm{~s}^{-1}$ (Fig. 12d). Moreover, estuary width correlates with bar length within this range (Fig. 12a,c). Bar length correlates better with estuary width than with peak tidal current velocity, which is described by:

$l=0.97 W^{0.87}$

Furthermore, the bar shape correlates with estuary width: sidebars occur in smaller channels and channels with a lower aspect ratio, while u-shaped bars occur on the higher end of the widths and aspect ratios (Fig. 12c,e).

Bar length scales with tidal prism (Fig. 12f) with a goodness of fit of 0.48 . Nevertheless, the approximate multiplication factor that the confidence limits plot higher or lower than the regression indicates scatter of an order of magnitude. The scatter occurs for two reasons: half of the tidal prism data was retrieved from the dataset of Manning (2007), for which Townend (2005) calculated that the error may be approximately $30 \%$. The second reason is that we estimated the local tidal prism based on the location of the tidal bar within the estuary. These results thus provide an initial indication of the relation that is present between tidal prism and bar dimensions. Possibly, the use of measured surface area in combination with tidal amplitude would result in a better prediction of the along-channel variation in bar patterns, but this is beyond the scope of this paper.

The braiding index mainly depends on estuary width and aspect ratio (Fig. 12b). For equal tidal current magnitude, the braiding index increases with estuary width. However, for the same estuary width, the braiding index may vary between 1 and 5 . Local width is thus insufficient to predict braiding index.

For all measured estuaries, bar height equals estuary depth within a factor 1.5 (Fig. 12g). In addition, the standard deviation of bar height falls within the tidal range of the estuary. For low estuary depths, the Parrett estuary (UK) seems an outlier with a tidal range of almost $8 \mathrm{~m}$ at the mouth. However, in this case the estuary is small (width 100$500 \mathrm{~m}$ and depth approximately $4 \mathrm{~m}$ ), resulting in a much smaller tidal range $(2 \mathrm{~m})$ within the estuary. 

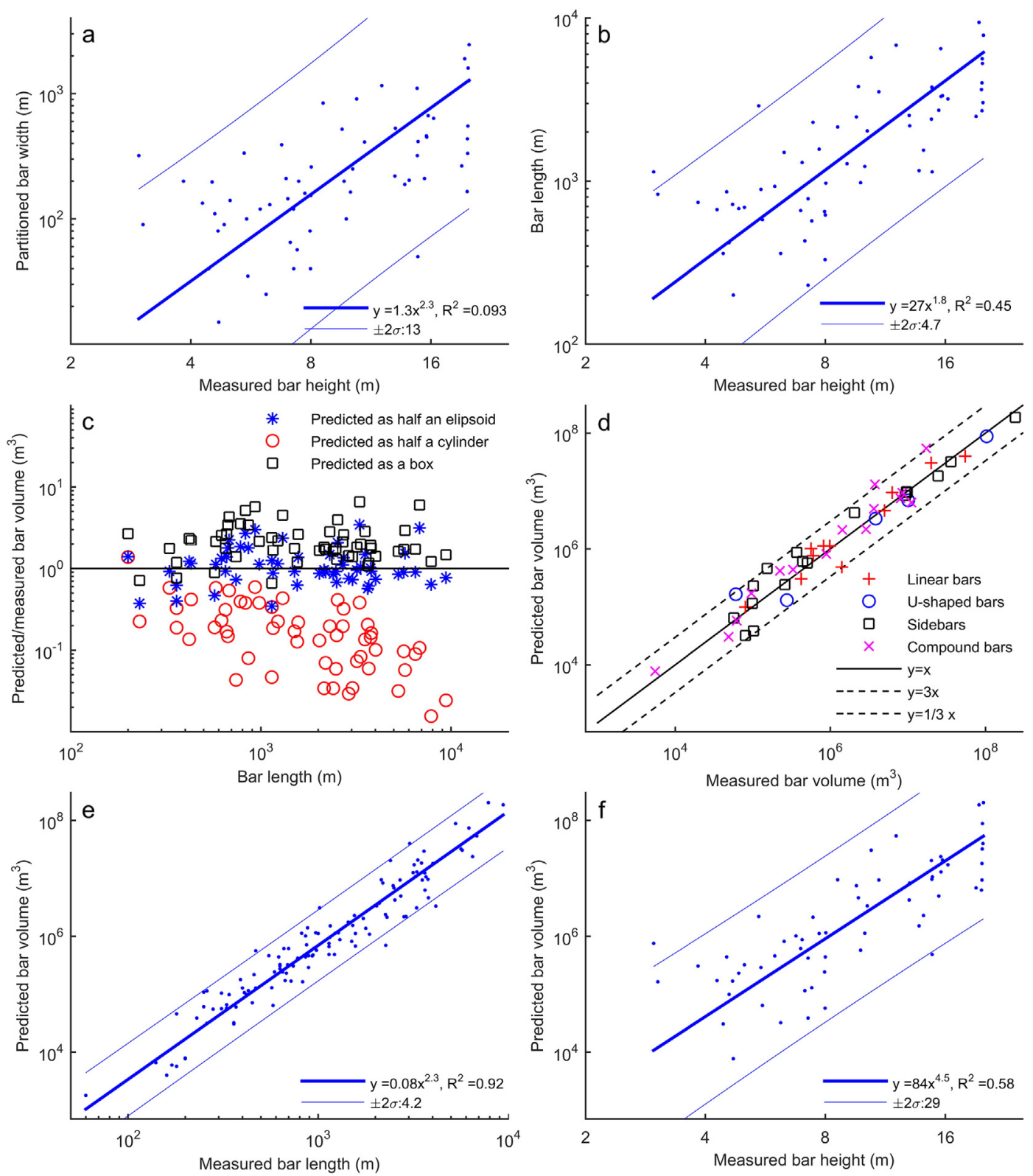

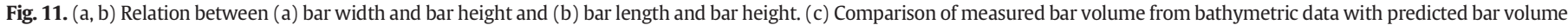

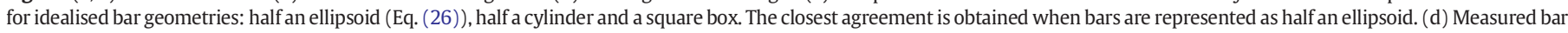

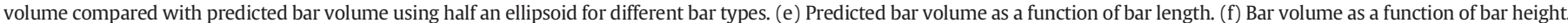

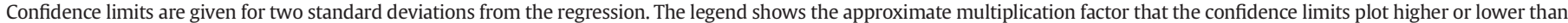
the trend.

\subsection{Dependence of bar shape and braiding index on water level}

The braiding index and bar shape depend strongly on water level as illustrated by Figs. 13 and 14. For example the Western Scheldt shows how bar type may alter from sidebar to linear bar in the transition from low water to higher water (Fig. 13c,e,g). Length-to-width ratios of non-partitioned bars support this. It may vary from 2.3 at low water, to 5.5 at higher water and 2.9 at mean sea level. Other estuaries show similar trends. For example the Broad River estuary shows a ushaped bar with a length-to-width ratio of 2.6 that alters to a linear bar with a ratio of 15.6 for increasing water levels (Fig. 13d,f,h). In addition, the braiding index changes: from 1.5 to 3 and at mean sea level to 2 in Western Scheldt and from 2.5 to 2 in the Broad River estuary (Fig. 13b,d,f). These results imply that u-shaped bars and sidebars may occur as linear bars under higher water levels and that the braiding index is highly sensitive to water level in imagery.

Fig. 14 shows the variation of bar shape and braiding index at different bar locations in three estuaries for which bathymetry data was available. Since estuary width is constant for different water levels, the variation of bar shape and braiding index at a specific bar location can be seen in the vertical aligned markers. The variation caused by water level alterations over a tidal cycle spans almost an order of magnitude for both length-to-width ratio and bar length (Fig. 14). This is similar to the variation that occurs within our dataset of all 190 bars. Similarly, the variation of braiding indices that occurs for a specific width is almost the same for the full dataset as for one location at different water levels.

Nevertheless, the measurements from aerial photographs were taken between mean sea-level and low water level. Within this range, 

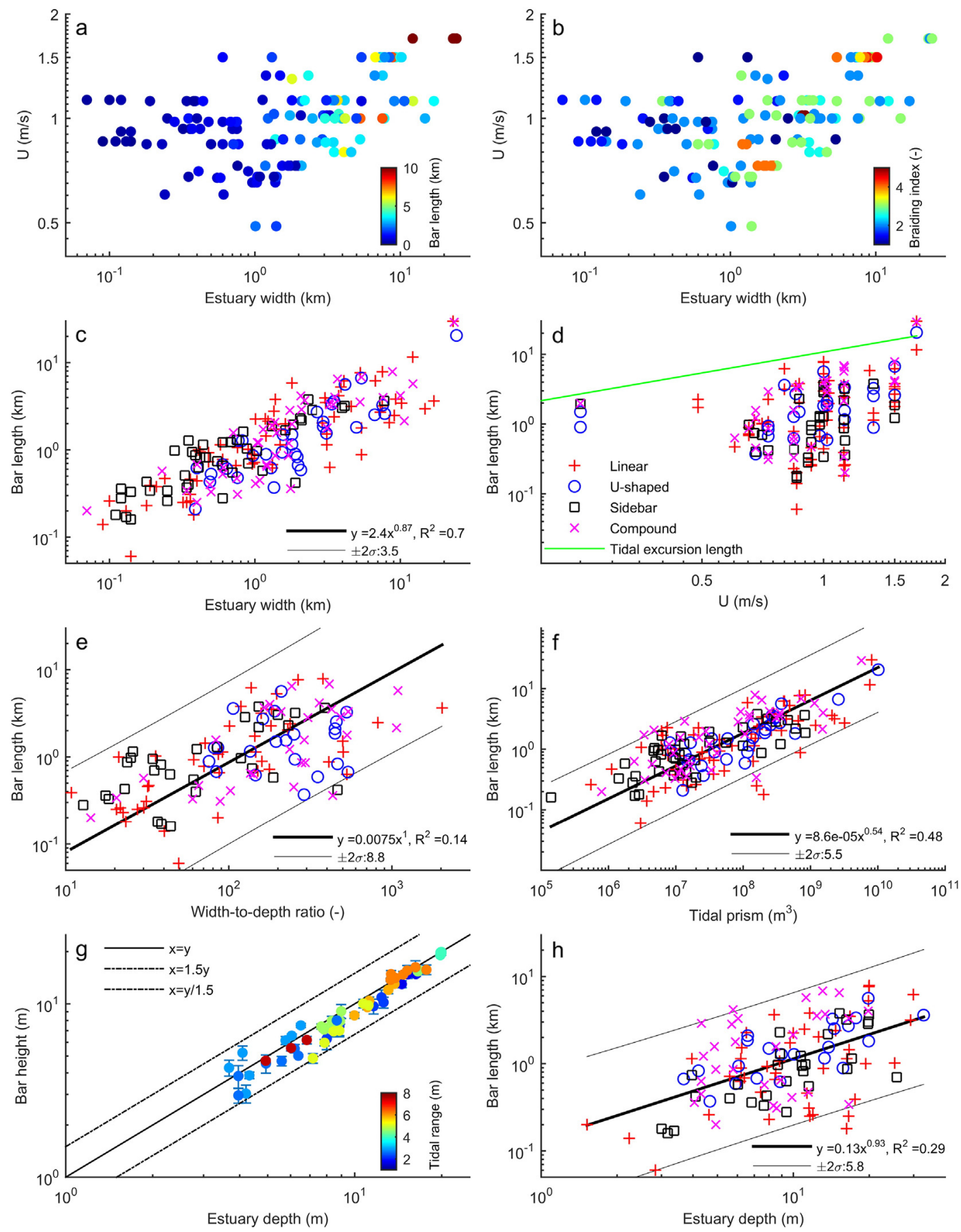

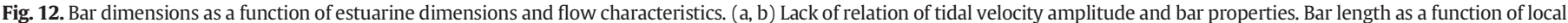

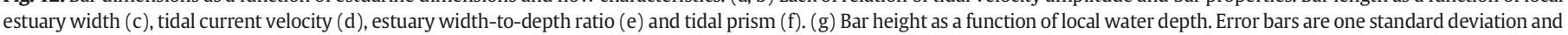

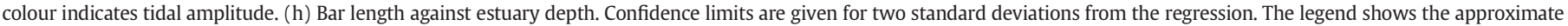
multiplication factor that the confidence limits plot higher or lower than the trend.

the uncertainty is limited to about a factor of two (Fig. 8d,e,f), which is reasonable given the scatter in the full dataset of estuarine bars. Fig. 8d,e,f shows that apparent bar dimensions are particularly sensitive to water level above mean sea level, when they are increasingly flooded. This uncertainty is smaller than the degree to which the bars collapse on a trend with limited scatter, before and after they were partitioned.

\subsection{Comparison of theory and data}

We compared the data with bar length predictions from the theoretical model (Schramkowski et al., 2002) for the same width, depth and tidal current velocity as for the gathered dataset (Fig. 15). We assumed here, that all other estuarine properties such as sediment properties and bottom roughness are equal for all estuaries for a lack of more detailed data (see default values in Table 1). Theoretical model results of bars are in the same order of magnitude as natural estuaries. For the same range of estuary dimensions as the natural estuaries used in this study, theory predicts bar lengths of 500-30,000 m. Both theory and data show bar lengths of 3-40 times bar width (Figs. 5 and 10).

Bar theory predicts bar length within the same order of magnitude in case of large bars, which are tens of kilometres long (Fig. 15a,b). In contrast, the length of shorter bars is overpredicted by one or two orders 

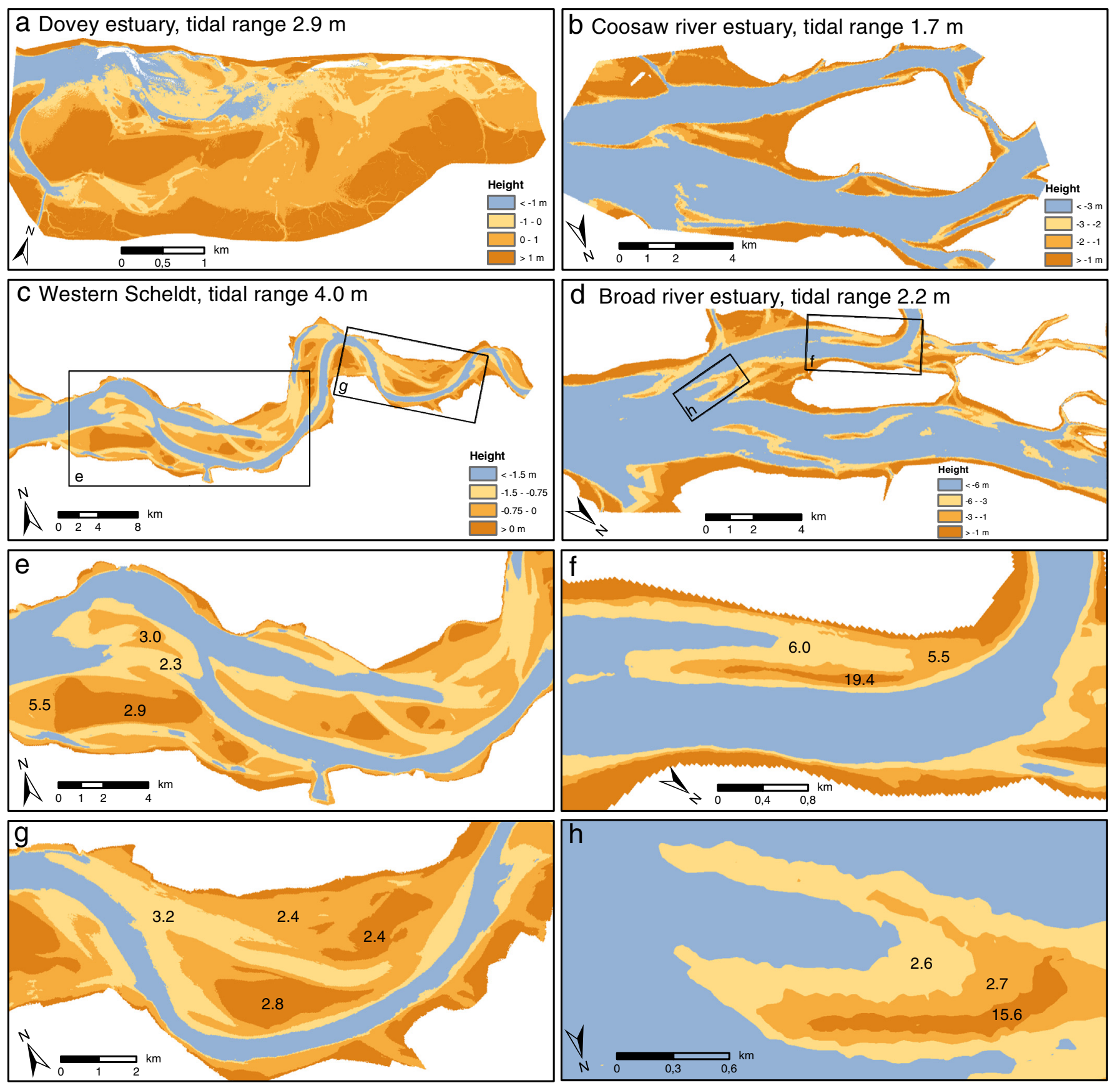

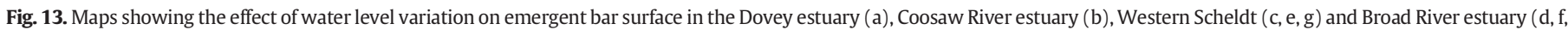
h). Values in e-h indicate the length-to-width ratio of the bar at a specific water level.

of magnitude. In all cases, bar theory predicts bar lengths in the order of the tidal excursion length (Fig. 15c), while data shows bar length to be up to an order of magnitude smaller. Surprisingly, tidal theory of Schramkowski et al. (2002) predicts bar length reasonably well when the aspect ratio is assumed to be 2000 for all estuaries (not shown here). This shows that the theory is not capturing the observed trends, or that the theory is not valid for fully developed bars, unlike the successful application of river bar theory to fully developed patterns (Kleinhans and van den Berg, 2011).

For aspect ratios below 100 , the bar theory predicts a braiding index of 1 (Fig. 15d). In natural estuaries a range of braiding indices between 1 and 3 occurs for aspect ratios between 10 and 100. Bar theory predicts fairly similar braiding indices for aspect ratios higher than 100. Bar theory thus underpredicts the braiding index for relatively narrow and deep estuaries. Moreover, the quality of bar length prediction also increases for systems with a high aspect ratio or a large width (Fig. 15a,b).

\section{Discussion}

Below, we will first compare the range of bar shapes and dimensions that occur in natural estuaries with results from studies on river bars and laboratory scale-experiments. Thereafter, we will compare the results with hypotheses from physics-based bar theory and previous studies, which enables us to assess the usability of theoretical models for prediction of real world bar patterns. Then, we link the bar dimensions with hydrodynamic and geometrical properties of estuaries. Finally, we 

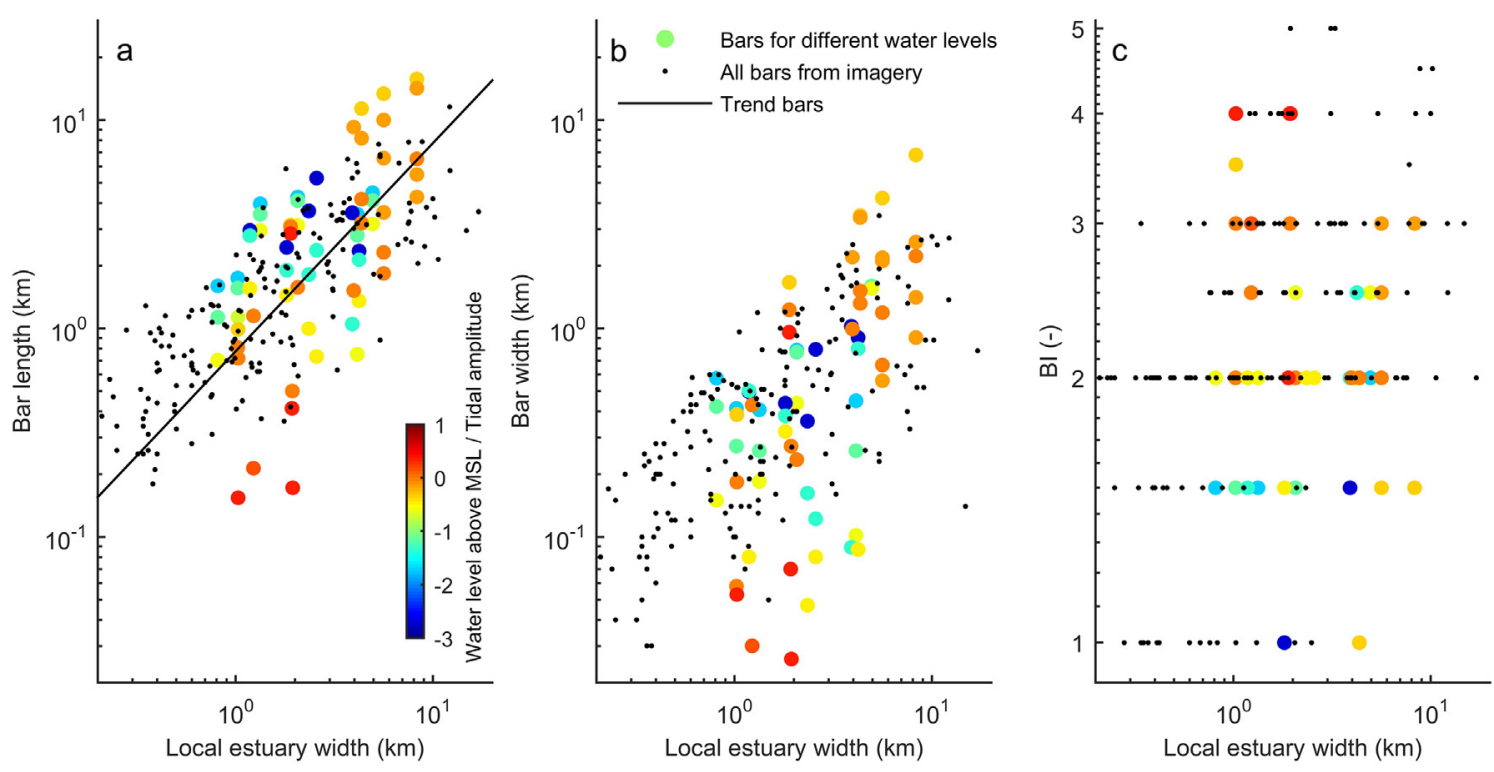

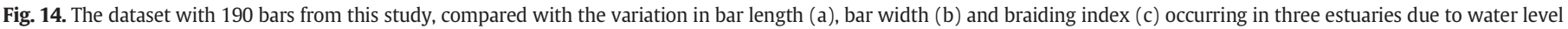
variations. Vertically aligned circles represent one bar for different water levels, where colour indicates water level above MSL normalised by tidal range.

describe the major implications for reconstruction of bar architecture by geologists and for future studies on bar patterns.

\subsection{Bar dimensions in data and theoretical models}

We found that bar shapes and dimensions in natural estuaries are similar to bars in braided rivers (Kelly, 2006) and in laboratory scale-experiments (Fig. 16). Bars in estuaries are on average 6.9 times longer than their width, which is more elongated than bars in rivers, where bars are 4.95 times longer than their width. We obtained this result after partitioning of the bar width based on the number of barb channels (Fig. 9). Before partitioning (Fig. 10a), bar lengths are on average 3.3 times their width to the power of 0.9 , which is very similar to the relation found for model results of braided rivers $(l=2.98 w)$ (Schuurman et al., 2013).

Our results are in good agreement with studies on river bars after considering the difference in methodology for measuring bars (Kelly, 2006; Schuurman et al., 2013). Kelly (2006) mainly measured bars as single linear bars without intersecting channels, while Schuurman et al. (2013) recorded bar length and width of full bar complexes including cross-bar channels. They found that river bar length is well predicted by theoretical models, while the braiding index is overpredicted in case of amalgamated braid bars. The methodology of Schuurman et al. (2013) resembles our methodology before partitioning, whereas the methodology of Kelly (2006) is similar to our methodology after partitioning bar width.

Until now, the forming mechanism of mutually evasive channels is unknown. As an example, we describe three theories for the formation of a u-shaped bar. U-shaped bars are better developed in estuaries than on open coast. For that reason, Wood (2004) hypothesised that these bars only form when the ebb- and flood-dominated channels are well-developed. In shallow-water settings, sandbanks spread laterally, merge with each other, and become dissected by ebb- and flooddominated channels. Potential explanations for the formation of a ushaped bar are (1) one current depositing sediments in a fan shape, while the other current evades the fan, (2) a tidal channel forming an unsuccessful chute cutoff and (3) linear bars connecting by lateral migrations (Sambrook Smith et al., 2006; Dalrymple and Choi, 2007).

Furthermore, we found relations between bar dimensions and relations with bar volume (Eq. (24), Figs. 10-11). In principle, it should be possible to predict bar length and width with bar height. Nevertheless, predictions may be off by an order of magnitude due to the scatter and as indicated by the lower $R^{2}$ values. Bar volume is best represented as half an ellipsoid (Fig. 11c), which allows to predict bar volume within a factor 3 if all bar dimensions are measured (Fig. 11d). Prediction of bar volume with bar length works better (Eq. (27), Fig. 11e) than prediction with bar height (Fig. 11f). This suggests that bar volume may be mispredicted by an order of magnitude when bar height from a single outcrop or drilling core is used.

Wood (2004) collected bar width and height from geological outcrops and presented data on tidal ridges in open oceans, river mouths, heads of bays and tidal coasts (Off, 1963). For geological outcrops, Wood (2004) found bar heights ranging from 1.4-6.8 $\mathrm{m}$ and bar widths from 380 to $1800 \mathrm{~m}$. For the modern tidal sandbank data (Off, 1963), Wood (2004) found typical median values for bar length (12 km), width $(1.6 \mathrm{~km})$ and height $(9.2 \mathrm{~m})$. The data we collected for estuarine systems consist off considerably smaller bars: median length is $1.1 \mathrm{~km}$ and width is $0.3 \mathrm{~km}$. The variation in bar height is very similar in our dataset, with a median of $8.6 \mathrm{~m}$. The largest bars in our dataset have similar dimensions as the smallest bars in the dataset of Off (1963). This may be explained by the environment in which the data were collected. Many bars measured by Off (1963) were collected in offshore environments, such as bars in the northern end of the Persian Gulf, which also means that they were formed by a different mechanism (Dyer and Huntley, 1999). In contrast, our data is limited to bars within estuarine systems, where bars are significantly smaller. Nevertheless, the trends on length-to-width ratios of bars are very similar in both datasets. Bars in Offs dataset show slightly more elongated shapes than bars in estuaries with lengths on average 9.9 times longer than their width.

\subsection{Applicability of the theoretical models}

Given similar flow velocities in a large range of estuary scales, bar theory consistently overpredicts bar dimensions by an order of magnitude in the case of small estuaries. Neither imposing aspect ratios of natural estuaries (Fig. 16, Eq. (24)) nor using a constant depth results in well-predicted bar dimensions. Better predictions were found for the braiding index which depends mostly on local channel aspect ratio in the theories. We conclude that the theory underpredicts the strong dependency of bar length and braiding index on estuary width as found in our data and for rivers. 

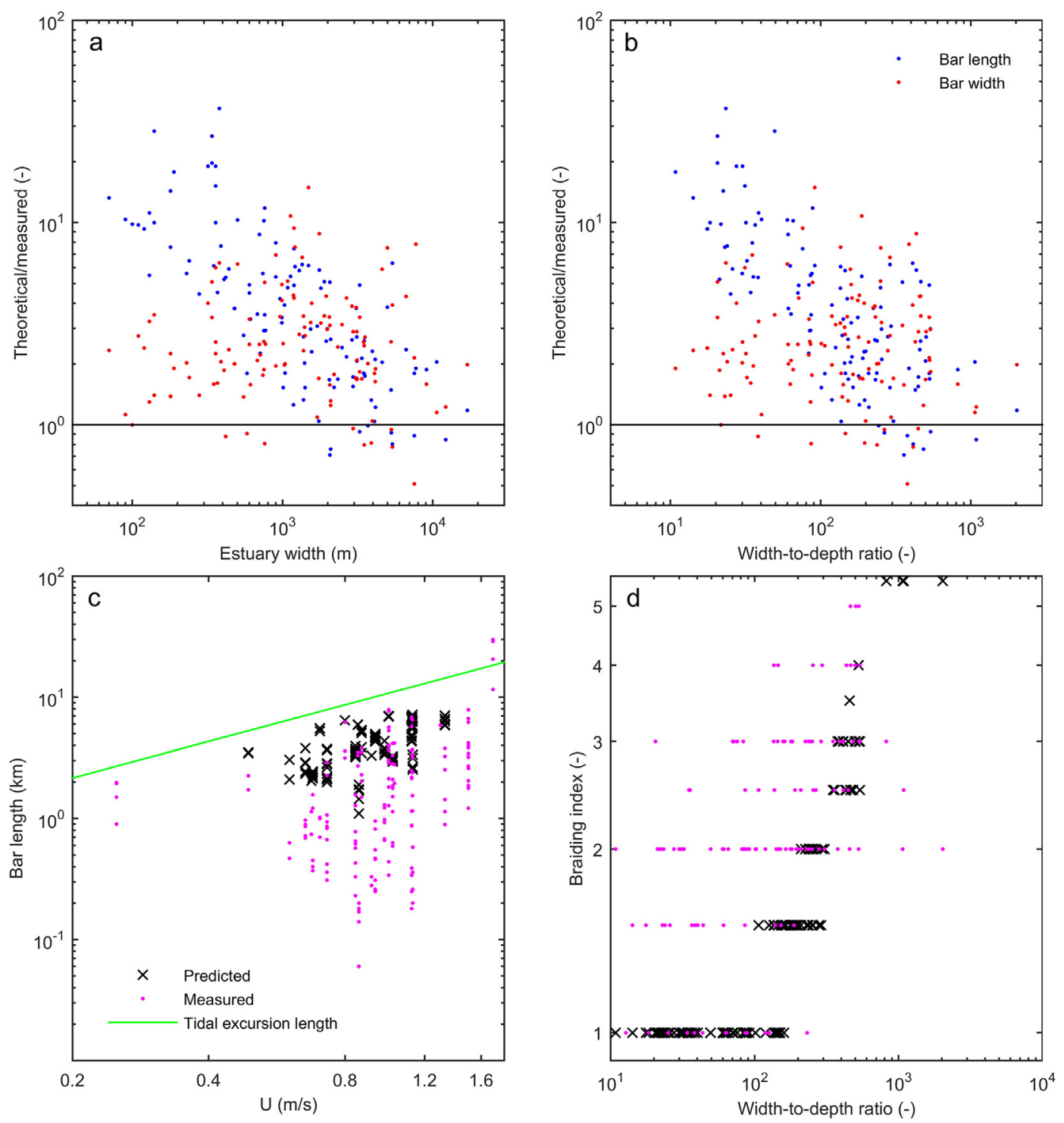

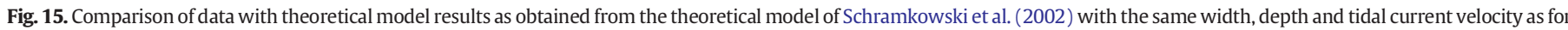
the data.

We assumed that properties such as sediment properties and bottom roughness are equal for all estuaries, which in principle may cause a misprediction of bar properties. Nevertheless, the sensitivity analysis showed that bar length is rather insensitive to grain size, bed slope effect and estuary width in tidal theory. Bed slope effect only has a minor influence on the braiding index, while estuary width clearly alters the braiding index (Fig. 7). Only the friction coefficient may influence bar length such that it alters by an order of magnitude. Longer bars are predicted for lower friction. In conclusion, theoretical model predictions are only slightly sensitive to the default parameters as specified in Table 1, meaning a rather general validity of our results.

An important assumption in linear theory is that the perturbations have a small amplitude relative to water depth, to avoid nonlinear effects becoming important. This means that both agreement and mismatch between data and theory can be due to a problem in the theory and due to deviations between incipient bars and fully developed bars. For rivers, bar theory works quite well with accurate bar length and braiding indices despite the full nonlinear development of the bars, which can suggest that something similar should hold for bars in estuaries if there are sufficient similarities in the processes. However, we found very large deviations between trends and magnitudes in the data and the predictions. Future tests with numerical models and experiments may show whether incipient bars are greatly different from fully developed bars. This means that we presently lack understanding of the formative mechanism of sand bars in estuaries.

\subsection{What determines bar properties?}

Bar length is often much shorter than tidal excursion length and bar length is independent of the amplitude of tidal current in our dataset, in contrast with hypotheses from previous theory (Seminara and Tubino, 2001; Schramkowski et al., 2002). So the hypothesis that bar length depends on system width - which was proposed in river theory (Kleinhans and van den Berg, 2011) and suggested for tidal systems (Dalrymple and Rhodes, 1995; Seminara et al., 2001; Dalrymple and Choi, 2007) - is more appropriate for tidal systems than the hypothesis from tidal theory, which states that bar length depends of the amplitude of tidal flow velocity. Previous authors proposed for bar length a ratio of 6-10 times channel width in tidal systems (Seminara et al., 2001) and 6 times channel width for tidal creeks (Dalrymple and Rhodes, 1995). Our 


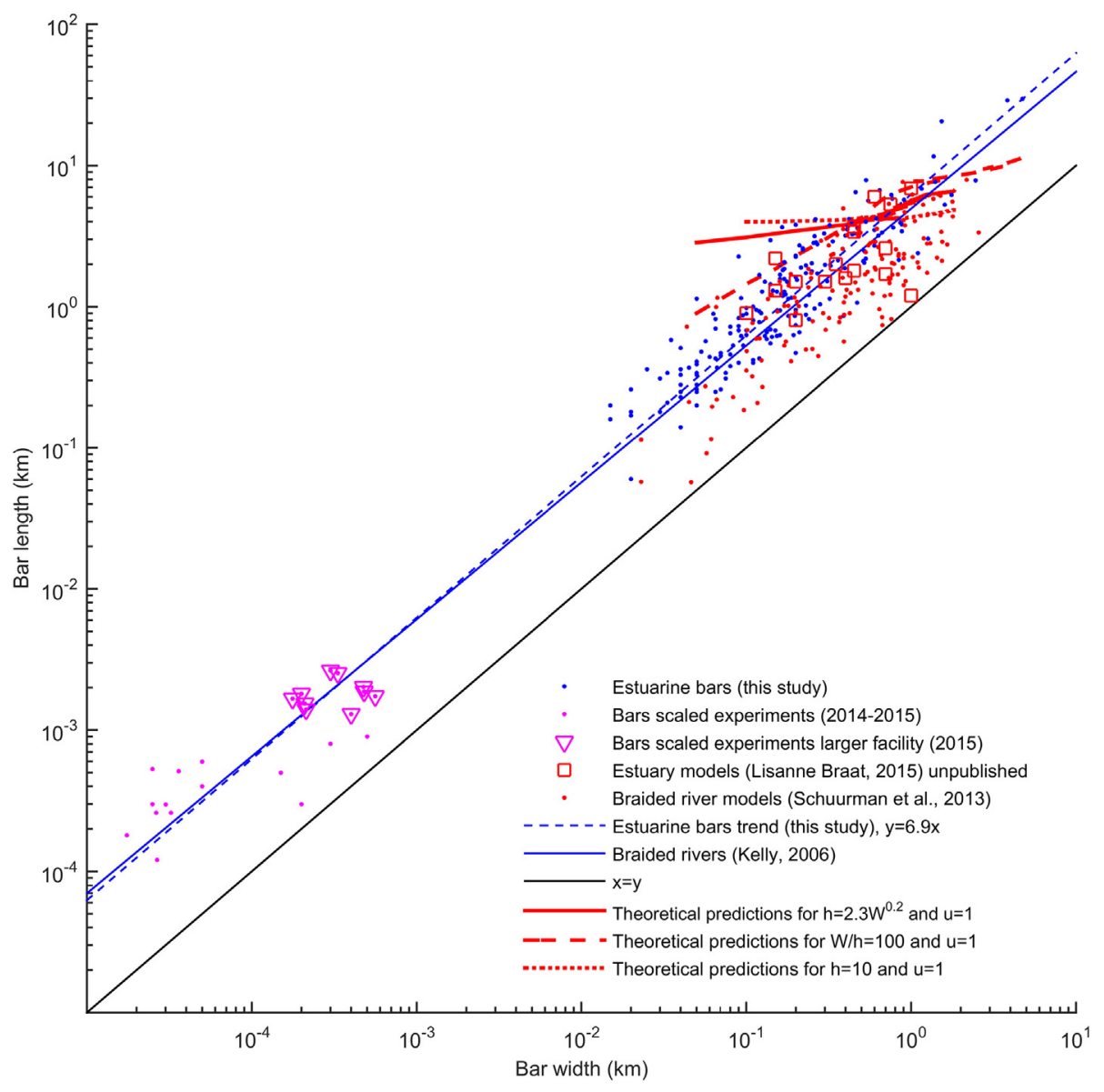

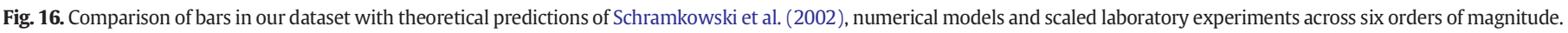

data suggests that bar length for estuaries may rather be of the same magnitude as the estuary width (Eq. (28)).

The dataset with tidal bars includes some constrained and vegetated bars. For rivers with meandering, where floodplain formation is important for the pattern, that would have been a problem (Kleinhans and van den Berg, 2011). However, the dimensions of estuarine sand bars are related to estuary width, regardless how that width came about. For estuaries, the effects of constraints and vegetation on bar shapes and dimensions are thus undiscernible (Fig. A.18).

The Brahmaputra River showed a power relation between bar length and river discharge (Ashmore, 2001). Our data resulted in a broad brush relation for a similar relation for bar length in estuaries: on average larger bars occur in estuaries with larger local tidal prisms (Fig. 12f). To capture the along-channel variation in bar patterns within an estuary, we may require a more accurate estimate of the local tidal discharge or a bar specific estimate, which equates to the upstream tidal prism plus any river discharge. A possible estimation could be made with the estuary shape and tidal range, since we often lack data on tidal prisms or the quality of these predictions is low (Townend, 2005).

Field observations and numerical model results for estuaries imply that more braided bars form when the aspect ratio increases (Dalrymple and Rhodes, 1995; Hibma et al., 2003; Toffolon and Crosato, 2007). As a threshold, an aspect ratio of approximately 100 is suggested for the transition from alternate bars to multiple bars (Dalrymple and Rhodes, 1995; Hibma et al., 2003). Both theoretical models and data in this study show that the braiding index increases with increasing estuary width and increasing aspect ratio (Figs. 5 and 7). This is similar to trends found in river theory, where aspect ratio is considered the major control on the braiding index (Struiksma et al.,
1985; Schielen et al., 1993; Hibma et al., 2003; Kleinhans and van den Berg, 2011). Bar theory for tidal systems predicts that the braiding index depends on tidal current velocities for wide channels and that bar length reduces with higher braiding indices, which does not agree with our data.

\subsection{Applications}

Geological architecture of tidal bar dimensions and thus reservoir size has been estimated with the median, 10th percentile and 90th percentile of modern tidal systems (Wood, 2004), which is rather inaccurate because this assumes independence on estuary dimensions and properties of tidal flow. We found that bar dimensions in estuaries are an order of magnitude smaller than the bars in the dataset of Off (1963), except for bar height.

However, the surface metrics of tidal bars that we collected cannot directly be linked to the subsurface metrics without relying on an empirical preservation ratio between feature height determined from surface morphology and subsurface architecture (Allen, 1984; Paola and Borgman, 1991; Bridge and Best, 1997; Straub et al., 2009; Ganti et al., 2011). Typical preservation ratios for ripples, dunes and river bars are 0.1-0.3 (Storms et al., 1999; Blom and Kleinhans, 2008; van de Lageweg et al., 2015). Although such generalisations are likely to extend to tidal systems, there clearly is a need for further study for application in process-driven reservoir characterisation.

Our analyses showed which factors determine bar dimensions and braiding index. These factors are mainly related to estuary dimensions, for which we have no predictors yet. Previous studies hypothesised that bar height increases with the lateral distance between bars 
(Allen, 1968), which increases with water depth according to Huthnance (1982). From these relations, one can derive an expression for the braiding index and bar width as a function of water depth. However, these relations would conflict with the hypotheses of Dalrymple and Rhodes (1995), who suggested that narrower banks typically occur in deeper channels. Swift and Field (1981) also documented a systematic decline in the length and width of tidal sandbanks as water depth increases. In short, we require a predictor for estuary width, such as the reference width in river systems (Kleinhans and van den Berg, 2011). Consequently, similar empirical bar pattern predictors may work successfully for estuaries, such as the potential stream power.

Future experiments and numerical modelling will allow us to systematically vary initial and boundary conditions to explore further what determines bar patterns. The empirical relations provided here will form a reference frame for comparison to experiments, analytical and numerical models and provide an estimate of bar dimensions when limited data is available. Additionally, an understanding of what determines the equilibrium bar pattern will enable us to study the evolution of sand bar patterns over time.

\section{Conclusions}

To investigate tidal bar patterns we collected a dataset on sand bar shapes and dimensions in funnel-shaped alluvial estuaries, mainly located in the USA and Europe. Comparison with braided river data shows that bars in estuaries are similar but 30\% more elongated, being on average 6.9 times longer than their partitioned width. Bar height in estuaries approximates the local estuary depth. Bar shapes in estuaries show unique features, such as the mutually evasive ebb and flood tidal channels, but in other aspects resemble river bars. However, until their formative mechanisms are better understood, it remains unclear to which extent linear, u-shaped, side- and compound bars in estuaries are similar to unit and compound bars in rivers. U-shaped, side- and compound bars are on average 2-3 times wider than linear bars, which is explained by barb channels, which may either be interpreted as remnants of cross-bar channels or of the amalgamation of smaller bars. After dividing up the bars at the barb channels, we found a similarity collapse of all bar types for the length-to-width ratio.

We tested a linear stability theory for bar properties in which predicted bar length strongly depends on the amplitude of tidal current or tidal excursion length. Measured bar dimensions, in contrast, show the strongest relation with estuary width. Given that estuaries of a wide range of sizes only exhibit a narrow range of flow velocities, the bar theory of Schramkowski et al. (2002) predicts bars of similar sizes regardless the size of the estuaries. In particular, the theory overpredicts bar dimensions in small estuaries by an order of magnitude. The theory underpredicts the strong dependency of bar length and braiding index on the estuary width as found in the data and for rivers. Better predictions were found for the braiding index which depends mostly on local channel aspect ratio. We present empirical relations for bar dimensions and for bar length as a function of local estuary width. The new relations may aid comparisons between experiments, models and natural systems, and may be applied in outcrop interpretation.

\section{Acknowledgments}

This research was supported by the Dutch Technology Foundation STW (grant Vici 016.140.316/13710 to MGK, which is part of the Netherlands Organisation for Scientific Research (NWO), and is partly funded by the Ministry of Economic Affairs). This work is part of the Ph.D. research of JRFWL and B.Sc. research of SAHW. We are grateful to George Schramkowski for his help and making his code available and to Maarten Zeylmans van Emmichoven for his GIS support. Discussion with Tjalling de Haas, Wietse van de Lageweg and Lisanne Braat and reviews by Ian Townend and one anonymous reviewer helped to improve the manuscript. The authors contributed in the following proportions to conception and design, data collection, modelling, analysis and conclusions, and manuscript preparation: JRFWL (50, 70, 60, 50, $70 \%)$, MGK (50, 0, 10, 30, 25\%), SAHW (0, 30, 0, 10, 0\%), $\operatorname{MvdV~(0,~0,~} 30$, $10,5 \%)$.

Maps. KML file containing the locations of tidal bars used in this study, formatted for Google maps.

\section{Appendix A. Supplementary data}

Supplementary material consist the list with estuaries used in this study, bar data, joined with estuary dimensions and tidal conditions from the literature. A kml-file with the bar locations is available in the online supplementary material. Supplementary data associated with this article can be found in the online version, at doi: http://dx.doi.org/ 10.1016/j.earscirev.2016.08.004. These data include the Google maps of the location of the bars used in this article.

\section{References}

Alam, R., Islam, M.S., Hasib, M.R., Khan, M.Z.H., 2014. Characteristics of hydrodynamic processes in the Meghna Estuary due to dynamic whirl action. IOSR J. Eng. 04 (06), 39-50.

Allen, J.R.L., 1968. Current ripples, their relation to patterns of water and sediment motion. North-Holland Pub. Co., Amsterdam.

Allen, J.R.L., 1984. Sedimentary Structures: Their Character and Physical Basis. Elsevier, Amsterdam, the Netherlands.

Ashmore, P.E., 2001. Gravel-Bed River V, Chapter Braiding Phenomena: Statics and Kinetics. New Zealand Hydrological Society Inc., Wellington, New Zealand, pp. 95-114.

Ashworth, P.J., Best, J.L., Roden, J.E., Bristow, C.S., Klaassen, G.J., 2000. Morphological evolution and dynamics of a large, sand braid-bar, Jamuna River, Bangladesh. Sedimentology 47 (3), 533-555.

Billy, J., Chaumillon, E., Féniès, H., Poirier, C., 2012. Tidal and fluvial controls on the morphological evolution of a lobate estuarine tidal bar: the Plassac Tidal Bar in the Gironde Estuary (France). Geomorphology 169, 86-97.

Blom, A., Kleinhans, M.G., 2008. Estimating bed form height from sorting preserved in sedimentary records of river dunes, deltas and bars. River, Coastal and Estuarine Morphodynamics (RCEM 2007). Taylor and Francis, London, pp. 641-668.

Blondeaux, P., Vittori, G., 2016. A model to predict the migration of sand waves in shallow tidal seas. Cont. Shelf Res. 112, 31-45.

Bridge, J.S., 1993. The interaction between channel geometry, water flow, sediment transport and deposition in braided rivers. Geol. Soc. Lond., Spec. Publ. 75 (1), 13-71.

Bridge, J., 2003. Rivers and Floodplains. Blackwell Publishing, Malden, Mass 491 pp.

Bridge, J., Best, J., 1997. Preservation of planar laminae due to migration of low-relief bed waves over aggrading upper-stage plane beds: comparison of experimental data with theory. Sedimentology 44 (2), 253-262.

Bridge, J.S., Tye, R.S., 2000. Interpreting the dimensions of ancient fluvial channel bars, channels, and channel belts from wireline-logs and cores. AAPG Bull. 84 (8), 1205-1228.

Cant, D.J., Walker, R.G., 1978. Fluvial processes and facies sequences in the sandy braided South Saskatchewan River, Canada. Sedimentology 25 (5), 625-648.

Coco, G., Zhou, Z., van Maanen, B., Olabarrieta, M., Tinoco, R., Townend, I., 2013. Morphodynamics of tidal networks: advances and challenges. Mar. Geol. 346, 1-16.

Colombini, M., 2016. Stability of river bed forms. Marine \& River Dune Dynamics page Keynote.

Crosato, A., Mosselman, E., 2009. Simple physics-based predictor for the number of river bars and the transition between meandering and braiding. Water Resour. Res. 45 (3), W03424.

Dalrymple, R.W., Choi, K., 2007. Morphologic and facies trends through the fluvial-marine transition in tide-dominated depositional systems: a schematic framework for environmental and sequence-stratigraphic interpretation. Earth Sci. Rev. 81 (3), 135-174.

Dalrymple, R.W., Rhodes, R.N., 1995. Estuarine Dunes and Bars. Geomorphology and Sedimentology of Estuaries Vol. 53, pp. 359-422.

Dalrymple, R.W., Knight, R., Zaitlin, B.A., Middleton, G.V., 1990. Dynamics and facies model of a macrotidal sand-bar complex, Cobequid Bay-Salmon River Estuary (Bay of Fundy). Sedimentology 37 (4), 577-612.

Dalrymple, R.W., Zaitlin, B.A., Boyd, R., 1992. Estuarine facies models: conceptual basis and stratigraphic implications: perspective. J. Sediment. Res. 62 (6).

Davidson, N., Council, N.C., 1991. Nature Conservation and Estuaries in Great Britain. Nature Conservancy Council Peterborough.

de Swart, H., Zimmerman, J., 2009. Morphodynamics of tidal inlet systems. Annu. Rev. Fluid Mech. 41, 203-229.

Dodd, N., Blondeaux, P., Calvete, D., De Swart, H.E., Falqués, A., Hulscher, S.J., Różyń'ski, G. Vittori, G., 2003. Understanding coastal morphodynamics using stability methods. J. Coast. Res. 19 (4), 849-865.

Dyer, K.R., Huntley, D.A., 1999. The origin, classification and modelling of sand banks and ridges. Cont. Shelf Res. 19 (10), 1285-1330.

Engelund, F., Hansen, E., 1967. A monograph on sediment transport in alluvial streams. Technical Report, TEKNISKFORLAG Skelbrekgade 4 Copenhagen V, Denmark.

Ganti, V., Straub, K.M., Foufoula-Georgiou, E., Paola, C., 2011. Space-time dynamics of depositional systems: experimental evidence and theoretical modeling of heavy-tailed statistics. J. Geophys. Res. Earth Surf. 116 (F2). 
Gisen, J.I.A., Savenije, H.H., 2015. Estimating bankfull discharge and depth in ungauged estuaries. Water Resour. Res. 51 (4), 2298-2316.

Hey, R.D., Thorne, C.R., 1986. Stable channels with mobile gravel beds. J. Hydraul. Eng. 112 (8), 671-689.

Hibma, A., De Vriend, H.J., Stive, M.J.F., 2003. Numerical modelling of shoal pattern formation in well-mixed elongated estuaries. Estuar. Coast. Shelf Sci. 57 (5), 981-991.

Hulscher, S.J., de Swart, H.E., de Vriend, H.J., 1993. The generation of offshore tidal sand banks and sand waves. Cont. Shelf Res. 13 (11), 1183-1204.

Hume, T.M., Herdendorf, C.E., 1988. A geomorphic classification of estuaries and its application to coastal resource management-a New Zealand example. Ocean Shoreline Manag. 11 (3), 249-274.

Huthnance, J.M., 1982. On one mechanism forming linear sand banks. Estuar. Coast. Shelf Sci. 14 (1), 79-99.

Jeuken, M.C.J.L., Wang, Z.B., Keiller, D., Townend, I., Liek, G.A., 2003. Morphological response of estuaries to nodal tide variation. International Conference on Estuaries and Coasts, pp. 166-173.

Kelly, S., 2006. Scaling and Hierarchy in Braided Rivers and Their Deposits: Examples and Implications for Reservoir Modelling. Braided Rivers: Process, Deposits, Ecology and Management (Special Publication 36 of the IAS) Vol. 21, p. 75.

Kleinhans, M.G., van den Berg, J.H., 2011. River channel and bar patterns explained and predicted by an empirical and a physics-based method. Earth Surf. Process. Landf. 36 (6), 721-738.

Kleinhans, M.G., Braudrick, C., Van Dijk, W.M., Van de Lageweg, W.I., Teske, R., Van Oorschot, M., 2015a. Swiftness of biomorphodynamics in lilliput-to giant-sized rivers and deltas. Geomorphology 244, 56-73.

Kleinhans, M.G., Scheltinga, R.T., Vegt, M., Markies, H., 2015b. Turning the tide: growth and dynamics of a tidal basin and inlet in experiments. J. Geophys. Res. Earth Surf 120 (1), 95-119.

Komarova, N.L., Hulscher, S.J., 2000. Linear instability mechanisms for sand wave formation. J. Fluid Mech. 413, 219-246.

Leopold, L.B., Maddock Jr., T., 1953. The Hydraulic Geometry of Stream Channels and Some Physiographic Implications. Technical Report, U.S. Geological Survey, Professional Paper Vol. 252

Leopold, L.B., Wolman, M.G., 1960. River meanders. Geol. Soc. Am. Bull. 71 (6), 769-793.

Wood, L.J., 2004. Predicting tidal sand reservoir architecture using data from modern and ancient depositional systems, integration of outcrop and modern analogs in reservoir modeling. AAPG Mem. 80, 45-66.

Manning, A.J., 2007. Enhanced UK estuaries database: explanatory notes and metadata. Technical Report TR167, HR Wallingford Tech. Report, TR167, UK.

Meyer-Peter, E., Müller, R., 1948. Formulas for bed-load transport. Proceedings of 2nd Meeting: 297 International Association for Hydraulic Structures Research. IAHR, Stockhold, Sweden, pp. 39-64.

Off, T., 1963. Rhythmic linear sand bodies caused by tidal currents. AAPG Bull. 47 (2) 324-341.

Paola, C., Borgman, L., 1991. Reconstructing random topography from preserved stratification. Sedimentology 38 (4), 553-565.

Parker, G., 1976. On the cause and characteristic scales of meandering and braiding in rivers. J. Fluid Mech. 76 (03), 457-480.

Perillo, G.M., 1995. Geomorphology and Sedimentology of Estuaries vol. 53. Elsevier.

Pritchard, D.W., 1967. What is an Estuary: Physical Viewpoint. In: Lauff, G.H. (Ed.) Estuaries Vol. 83. American Association for the Advancement of Science, pp. 3-5.

Rice, S.P., Church, M., Wooldridge, C.L., Hickin, E.J., 2009. Morphology and evolution of bars in a wandering gravel-bed river; lower Fraser River, British Columbia, Canada. Sedimentology 56 (3), 709-736.

Sambrook Smith, G., Ashworth, P., Best, J., Woodward, J., Simpson, C., 2006. The sedimentology and alluvial architecture of the sandy braided South Saskatchewan River, Canada. Sedimentology 53 (2), 413-434.
Savenije, H.H., 2006. Salinity and Tides in Alluvial Estuaries. Elsevier.

Savenije, H.H., 2015. Prediction in ungauged estuaries: an integrated theory. Water Resour. Res. 51 (4), 2464-2476.

Schielen, R., Doelman, A., De Swart, H.E., 1993. On the nonlinear dynamics of free bars in straight channels. J. Fluid Mech. 252, 325-356.

Schramkowski, G.P., Schuttelaars, H.M., De Swart, H.E., 2002. The effect of geometry and bottom friction on local bed forms in a tidal embayment. Cont. Shelf Res. 22 (11), $1821-1833$.

Schuurman, F., Marra, W.A., Kleinhans, M.G., 2013. Physics-based modeling of large braided sand-bed rivers: bar pattern formation, dynamics, and sensitivity. J. Geophys. Res. Earth Surf. 118 (4), 2509-2527.

Seminara, G., Tubino, M., 2001. Sand bars in tidal channels. Part 1. Free bars. J. Fluid Mech. $440,49-74$

Seminara, G., Lanzoni, S., Pittaluga, M.B., Solari, L., 2001. Estuarine patterns: an introduction to their morphology and mechanics. Geomorphological Fluid Mechanics. Springer, pp. 455-499.

Storms, J.E., Dam, R.L.V., Leclair, S.F., 1999. Preservation of cross-sets due to migration of current ripples over aggrading and non-aggrading beds: comparison of experimental data with theory. Sedimentology 46 (1), 189-200.

Straub, K.M., Paola, C., Mohrig, D., Wolinsky, M.A., George, T., 2009. Compensational stacking of channelized sedimentary deposits. J. Sediment. Res. 79 (9), 673-688.

Struiksma, N., OlesenN, K., Flokstra, C., De Vriend, H.J., 1985. Bed deformation in curved alluvial channels. J. Hydraul. Res. 23 (1), 57-79.

Swift, D.J.P., Field, M.E., 1981. Evolution of a classic sand ridge field: Maryland sector, North American inner shelf. Sedimentology 28 (4), 461-482.

Swinkels, C.M., Jeuken, C.M., Wang, Z.B., Nicholls, R.J., 2009. Presence of connecting channels in the Western Scheldt Estuary. J. Coast. Res. 627-640.

Toffolon, M., Crosato, A., 2007. Developing macroscale indicators for estuarine morphology: the case of the Scheldt estuary. J. Coast. Res. 23 (1), 195-212.

Townend, I., 2005. An examination of empirical stability relationships for UK estuaries. J. Coast. Res. 1042-1053.

Townend, I., 2012. The estimation of estuary dimensions using a simplified form model and the exogenous controls. Earth Surf. Process. Landf. 37 (15), 1573-1583.

Townend, I., Wright, A., Price, D., 2000. An investigation of the gross properties of UK estuaries. EMPHASYS Consortium Modelling Estuary Morphology and Process, p. 73.

van de Lageweg W.I, Schuurman, F. Cohen, K.M., Dijk, W.M. Shimizu, Y., Kleinhans, M.G. 2015. Preservation of meandering river channels in uniformly aggrading channel belts. Sedimentology.

van Rijn, L.C., 1984. Sediment transport, part II: suspended load transport. J. Hydraul. Eng. 110 (11), 1613-1641.

van Rijn, L.C., 1993. Principles of Sediment Transport in Rivers, Estuaries and Coastal Seas. Aqua Publications, Amsterdam.

van Veen, J., 1950. Eb-en vloedschaarsystemen in de nederlandse getijwateren. Tijdschrift Koninklijk Nederlands Aardrijkskundig Genootschap Vol. 67, pp. 303-325.

Wang, Z.B., Hoekstra, P., Burchard, H., Ridderinkhof, H., De Swart, H.E., Stive, M.J.F., 2012. Morphodynamics of the wadden sea and its barrier island system. Ocean Coast. Manag. 68, 39-57.

Wolanski, E., 2014. Estuaries of Australia in 2050 and Beyond. Springer.

\section{Further reading}

Wright, L.D., Coleman, J.M., Thom, B.G., 1973. Processes of channel development in a hightide-range environment: Cambridge gulf-ord river delta, western Australia. J. Geol. 81 (1), 15-41. 